University of Tennessee Health Science Center

UTHSC Digital Commons

\title{
Developmental Expression of Rat Target of the Antiproliferative Antibody (rTAPA) Protein in the Brain
}

Clyde Dale Sullivan

University of Tennessee Health Science Center

Follow this and additional works at: https://dc.uthsc.edu/dissertations

Part of the Amino Acids, Peptides, and Proteins Commons, and the Neurosciences Commons

\section{Recommended Citation}

Sullivan, Clyde Dale, "Developmental Expression of Rat Target of the Antiproliferative Antibody (rTAPA) Protein in the Brain" (1998). Theses and Dissertations (ETD). Paper 265. http://dx.doi.org/10.21007/ etd.cghs.1998.0304.

This Thesis is brought to you for free and open access by the College of Graduate Health Sciences at UTHSC Digital Commons. It has been accepted for inclusion in Theses and Dissertations (ETD) by an authorized administrator of UTHSC Digital Commons. For more information, please contact jwelch30@uthsc.edu. 


\title{
Developmental Expression of Rat Target of the Antiproliferative Antibody (rTAPA) Protein in the Brain
}

\author{
Abstract \\ The present study defines the expression pattern of rTAPA (CD81) in the developing rat brain. rTAPA is a \\ member of the tetramembrane spanning family of proteins, and like other members of this family, \\ appears to be associated with the stabilization of cellular contacts. On immunoblots of the brain, rTAPA is \\ present in higher levels than any other tissue examined: muscle, tendon, peripheral nerve, cartilage, liver, \\ kidney, skin, and testicle. Immunohistochemical methods were used to define the distribution of rTAPA in \\ the brain. This protein is expressed by ependyma, choroid plexus, astrocytes, and oligodendrocytes, and \\ rTAPA is dramatically upregulated at the time of glial birth and maturation. At embryonic day 18 , the levels \\ of rTAPA are low, with most of the immunoreaction product associated with the ependyma, choroid \\ plexus, and the glia limitans. As development continues, the amount of rTAPA expressed in the brain \\ increases and at postnatal day 14 the levels approach those of the adult. This increase of rTAPA at \\ postnatal day 14 is due to the upregulation in the gray and white matter. Thus, rTAPA is found in all glial \\ cells and the level of this protein correlates with their maturation.

\section{Document Type} \\ Thesis

\section{Degree Name} \\ Master of Science (MS)

\section{Program} \\ Anatomy and Neurobiology

\section{Research Advisor} \\ Eldon E. Geisert, Jr.

\section{Keywords} \\ oligodendrocyte, astrocyte, gliogenesis, tetramenbrane spanning family

\section{Subject Categories} \\ Amino Acids, Peptides, and Proteins | Chemicals and Drugs | Medical Sciences | Medicine and Health \\ Sciences | Neurosciences

\section{Comments} \\ Two year embargo expired June 2000
}




\title{
Developmental Expression of Rat Target of the Antiproliferative Antibody (rTAPA) Protein in the Brain.
}

\author{
A Thesis \\ Presented for \\ The Graduate Studies Council \\ The University of Tennessee, Memphis
}

In Partial Fulfillment

Of the Requirements for the Degree

Master of Science

From the University of Tennessee

\author{
By \\ Clyde Dale Sullivan \\ June, 1998
}




\section{ACKNOWLEDGEMENTS}

This project was supported by the University of Tennessee, Memphis Health Science Center and the Spinal Cord and the Center for Excellence in Neuroscience provided graduate support. I would also like to thank Li Juan Yang, MD and Allison Stewart for their technical assistance, and my committee for there expertise and assistance. 


\begin{abstract}
The present study defines the expression pattern of rTAPA (CD81) in the developing rat brain. rTAPA is a member of the tetramembrane spanning family of proteins, and like other members of this family, appears to be associated with the stabilization of cellular contacts. On immunoblots of the brain, rTAPA is present in higher levels than any other tissue examined: muscle, tendon, peripheral nerve, cartilage, liver, kidney, skin, and testicle. Immunohistochemical methods were used to define the distribution of rTAPA in the brain. This protein is expressed by ependyma, choroid plexus, astrocytes, and oligodendrocytes, and rTAPA is dramatically upregulated at the time of glial birth and maturation. At embryonic day 18, the levels of rTAPA are low, with most of the immunoreaction product associated with the ependyma, choroid plexus, and the glia limitans. As development continues, the amount of rTAPA expressed in the brain increases and at postnatal day 14 the levels approach those of the adult. This increase of rTAPA at postnatal day 14 is due to the upregulation in the gray and white matter. Thus, rTAPA is found in all glial cells and the level of this protein correlates with their maturation.
\end{abstract}




\section{TABLE OF CONTENTS}

Chapter 1. Introduction 1

$\begin{array}{ll}\text { Chapter 2. Materials and Methods } & 7\end{array}$

$\begin{array}{ll}\text { Immunohistochemistry } & 7\end{array}$

Gel Electrophoresis and Immunoblot Method 8

$\begin{array}{ll}\text { Cell Cultures } & 9\end{array}$

In Situ Hybridization $\quad 10$

Chapter 3. Results 13

Developmental Regulation of rTAPA in the Brain $\quad 14$

Cellular Distribution of rTAPA 16

$\begin{array}{ll}\text { In Situ Hybridization } & 19\end{array}$

Distribution of rTAPA in the Developing Brain 22

Distribution of rTAPA in the Adult Brain 27

Chapter 4. Discussion 30

Cells Expressing rTAPA 32

Astrocyte Maturation $\quad 33$

Role of rTAPA $\quad 34$

$\begin{array}{ll}\text { Conclusion } & 37\end{array}$

List of References 39

$\begin{array}{ll}\text { Vita } & 47\end{array}$ 


\section{LIST OF FIGURES}

Figure 1 Blots of protein samples from different rat tissues. 15

$\begin{array}{ll}\text { Figure } 2 \text { rTAPA developmental graph. } & 17\end{array}$

$\begin{array}{ll}\text { Figure } 3 \text { Blots of stage specific glial markers. } & 18\end{array}$

Figure 4 AMP1 labeling of cultured glial cells. 20

Figure 5 In situ hybridization with rTAPA probes. 21

Figure 6 Immunohistochemistry of rTAPA in the rat brain. 23

Figure 7 Immunohistochemistry of rTAPA in the choroid. 26

Figure 8 Immunohistochemistry of rTAPA in the spinal cord. 29

Figure 9 Protein structure of rTAPA. 36 



\section{CHAPTER 1. INTRODUCTION}

Two major events in the final stages of central nervous system (CNS) development are the birth and maturation of glia. Glial cells born during this period form the majority of cells in the CNS and have a number of different functions. Within the brain and spinal cord both microglia (Flaris et al., 1993) and macroglia are present. This report focuses on the different types of macroglia: astrocytes, oligodendrocytes, ependymal cells, choroidal cells, and radial glia. The earliest generated glial cells are the radial glia (Misson et al., 1991). These cells are specifically associated with neuronal migration (Rakic, 1971; Caviness and Rakic, 1978; Hatten, 1990; Misson et al., 1991; Komuro and Rakic, 1993). Shortly following the emergence of the radial glia, the ependymal lining of the ventricular system develops and the choroid plexus forms (for review see, Del Bigio, 1995). The final populations of glial cells are born during the late embryonic period and extending into early postnatal life, a time when neurogenesis is ending (Ling and Leblond, 1973; Parnavelas et al., 1983). The majority of these cells differentiate into astrocytes and oligodendrocytes.

The number of glia in the mammalian neocortex is much greater than the number of neurons, particularly in larger brains. Many of the glia colonizing the neocortex originate as immature cells of the subventricular zone (Levison and Goldman, 1993; Zerlin et al., 1995). These cells migrate to the neocortex and either differentiate into a terminal cell type, i.e. astrocyte or oligodendrocyte, or continue to divide for a few generations before differentiating. Unlike neurons, there is no evidence that there is a laminar pattern to the timing of this development (Zerlin et al., 1995).

Gliogenesis, the birth of astrocytes and oligodendrocytes, is visible as early 
as embryonic day 12 in the developing CNS of rats, but the peak of gliogenesis does not occur until the second postnatal week of development (Hardy and Reynolds, 1991; LeVine and Goldman, 1988). Because glial colonization of the cortex largely takes place after neuronal migration, glia must be effectively integrated into the complex organization of developing neuronal systems. The mechanisms for this to occur must result in specific cellular interactions critical to neuronal and glial functions. These interactions include cues for cell survival and axon guidance; cell-cell contacts; myelin production by oligodendrocytes; astrocyte process contacts with blood vessels, synaptic junctions, and nodes of Ranvier (Zerlin and Goldman, 1997).

As astrocytes mature they induce the formation of a number of functional barriers such as the blood brain barrier. Development of the blood brain barrier begins during prenatal development (Wechslerr and Meller, 1967). It consists of the abutting of blood vessel basal lamina with astrocytic end feet to form a selectively permeable membrane. In 1997, Zerlin and Goldman proposed that perhaps all astrocytic progenitors that enter the cortex possess the same capability to contact vessels and may do so randomly. In this model of astrocyte development from subventricular cells, immature cells first migrate into the cortex along radial glial tracks. The immature cells respond to local cues as they migrate, perhaps sampling the environment with processes that come off tracks from time to time. The initial contact between an immature migratory cell and a blood vessel is random. They also suggest that blood vessels may provide signals that act upon uncommitted progenitor cells to restrict their fates to an astrocytic one. This hypothesis is supported by other data that suggest progenitor cells can have various fates depending on the environment. The work of 
Raff and colleges, 1983, with the O-2A progenitor cells clearly demonstrated that a single progenitor cell could differentiate into multiple cell types depending on environmental conditions. The determination of astrocytic fate by cues released from endothelial cells may explain the time frame of appearance and distribution of astrocytes and oligodendrocytes. If the developmental fates of glial progenitors are driven in part by growing blood vessels, then as the rates of vascular and pial surface growth slow, astrogenic signals will decrease and progenitors will have an increasing probability of developing along an oligodendrocyte pathway. This would result in a gradual transition from astrocyte to oligodendrocyte genesis. Also the number of astrocytes could provide an increasing source of astrocyte-derived growth factors (Barres and Raff, 1996) that further increase the probability of progenitors developing along an oligodendrocytic pathway.

Astrocytes are also associated with the glia limitans and the ependymal lining of the ventricular system. In addition, these cells regulate the levels of ions and other active molecules in the extracellular space which provide a homeostatic environment (Walz and Hertz, 1982; Ballanyi et al., 1987). Some of these extracellular molecules, e.g. tenascin and proteoglycans, play an integral role during the development of the nervous system as a substrate for neuronal migration and axon elongation (Silver et al., 1993; Rakic 1995). The molecules also establish functional boundaries important for guiding developing neuronal connections. Within the developing CNS, such boundaries are implicated in axonal guidance in the diencephalon (Silver 1984), the optic chiasm (Navascues et al., 1987; Silver et al., 1987), somatosensory barrel fields of the cortex (Cooper and Steindler, 1986), the midbrain (Garcia-Abreu et al., 1995), and 
the roof plate of the spinal cord and tectum (Wilkinson et al., 1987; Joosten and Gribnau, 1989). These boundaries play an integral role in axon guidance during embryogenesis by providing molecular cues that repel or attract growing axons.

Maturation of astrocytes is reflected in the regulated expression of specific proteins. Both protoplasmic astrocytes (found in the gray matter) and fibrous astrocytes (found in the white matter) express vimentin early in development and glial fibrillary acidic protein (GFAP) as they mature (Eng et al., 1971; Bignami and Dahl, 1973; Dahl, 1981; Pixley and de Vellis, 1984; Weir et al., 1984). The transition from an immature to a mature state is also marked by the expression of specific glycoconjugates that may be involved in pattern formation and the stabilization of neuronal contacts (Steindler et al., 1990; Geisert and Bidanset, 1993). While the astrocytes are forming a stable CNS environment, they acquire the potential to become reactive and form a glial scar (Berry et al., 1983). Many investigators believe that these reactive astrocytes contribute to the lack of axonal regeneration in the mammalian CNS (Reier and Houle, 1988).

Oligodendrocytes are the last major cell type born in the brain. The initial appearance of oligodendrocyte precursors appears to depend crucially on spatial information present in the developing CNS. Oligodendrocytes are derived from precursor cells that migrate from the ventral regions of the neural tube (Jones and Westbrook, 1996). During development, proliferating neuroepithelial cells of the spinal cord give rise to the major classes of neurons. Oligodendrocytes develop from precursors along the entire length of the spinal cord (Warf et al., 1991). In 1991, Warf and colleagues demonstrated that only precursors from the ventral and not dorsal embryonic day 14 rat spinal cord gives rise to 
oligodendrocytes. By embryonic day 18 , both the dorsal and ventral spinal cord has the capacity to generate these cells. This suggests that the precursors migrate to the dorsal regions of the spinal cord. Other areas of oligodendrocyte precursors include the optic nerve, midbrain, and forebrain. A group of cells in the ventricular zone of the diencephalon of the embryonic day 13 rat express mRNA for the platelet-derived growth factor, which is a proliferation trigger for oligodendrocyte precursors (Pringle et al., 1993). As these cells mature they migrate into the developing thalamus and hypothalamus as well as more dorsal regions including the cerebral cortex. Unlike neurons, oligodendrocytes continue to proliferate and colonize areas of the CNS for several months after birth in rats.

As oligodendrocytes mature they express many stage specific antigenic markers. Oligodendrocyte progenitors express the ganglioside $\mathrm{G}_{\mathrm{D} 3}$ (Goldman et al., 1984; Levi et al., 1987; LeVine and Goldman, 1988; Hardy and Reynolds, 1991). As maturation proceeds, a transitional period is entered when $\mathrm{G}_{\mathrm{D} 3}$ and galactocerebroside $(\mathrm{GC})$ are coexpressed. As the cells continue to develop, $\mathrm{G}_{\mathrm{D} 3}$ expression is lost and the expression of proteins marking mature oligodendrocytes begin (Hardy and Reynolds, 1991; Miller, 1996). Oligodendrocytes are fully mature when they begin to myelinate axons. The compact layers of membranes that form myelin sheaths contain a number of unique components. Some components associated with myelin are: GC (Raff et al., 1978; Raff et al., 1979), nucleotide-3-phosphohydrolase (McMorris, 1983), myelin basic protein (Reynolds and Wilkin, 1988), myelin-associated glycoproteins (Salzer et al., 1990; Quarles et al., 1992), and myelin/oligodendrocyte glycoprotein (Linington et al., 1984). Mature oligodendrocytes are essential for proper 
CNS function and are believed to prohibit axonal sprouting and growth (Caroni and Schwab, 1988).

Geisert and colleagues (1991a) recently identified a glial protein, the rat target of the antiproliferative antibody (rTAPA), that is a member of the tetramembrane spanning family. This family of proteins contains four transmembrane domains with one major extracellular loop and intracellular C- and N-terminal regions (Oren et al., 1990; Takahashi et al., 1990; Virtaneva et al., 1993). All of these proteins (CD9, CD37, CD53, CD63, TAPA-1, CO-029, R2, KAI1 and late bloomer) have considerable sequence homology at the amino acid level (Jennings et al., 1990; Oren et al., 1990; Kaprielian and Patterson, 1993; Yatomi et al., 1993; Dong et al., 1995; Kaprielian et al., 1995; Kopczynski et al., 1996). The only other member that has been found in the mammalian nervous system is CD9. It is expressed by Schwann cells in the peripheral nervous system (Kaprielian and Patterson, 1993) and appears to be expressed by oligodendrocytes in the CNS (Deissler et al., 1996; Nakamura et al., 1996). As with other members of this family, rTAPA appears to be associated with the formation of stable cellular contacts. The focus of the present study is to define the developmental regulation of rTAPA. 


\section{CHAPTER 2. MATERIALS AND METHODS}

\section{Immunohistochemistry}

Postnatal Sprague-Dawley rats of various ages were anesthetized with a mixture of xylazine $\left(13 \mathrm{mg} / \mathrm{kg}, \operatorname{Rompun}^{\circledR}\right)$ and ketamine (87 $\mathrm{mg} / \mathrm{kg}, \operatorname{Ketalar}^{\circledR}$ ) which was administered by intraperitoneal injection. The animals were perfused through the heart with a solution of $0.1 \mathrm{M}$ phosphate buffered saline (PBS, $\mathrm{pH} 7.5$ ) followed by $4 \%$ paraformaldehyde in $0.1 \mathrm{M}$ phosphate buffer ( $\mathrm{PB}, \mathrm{pH} 7.5)$. The brains and spinal cords were removed and placed in $4 \%$ paraformaldehyde for 4 hours. For cryoprotection the tissues were placed in a 30\% sucrose solution and allowed to sink. The brains from older rats were sectioned at 50 um with a freezing microtome (American Optical Corporation, New York). The brains from younger animals were cut at 50 um with a vibratome (Technical Products International, St. Louis, MO) or 10 um with a cryostat (Reichert Histostat, Buffalo, NY). Spinal cords were sectioned with a freezing microtome (American Optical Corporation, New York). All sections were stored in borate buffered saline $(\mathrm{pH} 8.4)$ at $4{ }^{\circ} \mathrm{C}$.

To begin the immunohistochemical staining process, sections were blocked for 2 hours at room temperature with $4 \%$ BSA (Sigma, St. Louis, $\mathrm{MO}$ ) in $0.2 \mathrm{M}$ borate buffered saline (BBS, $\mathrm{pH}$ 8.4). Sections were then placed in a solution containing the primary antibody at a concentration of approximately $20 \mathrm{ug} / \mathrm{ml}$ in $0.2 \mathrm{M}$ BBS with $1 \%$ BSA. They were incubated in this solution overnight at $4{ }^{\circ} \mathrm{C}$. Primary antibodies included the AMP1 monoclonal antibody (directed against rTAPA) and a polyclonal antibody directed against GFAP (Lipshaw, Pittsburgh, PA). Sections were washed 3 times for 10 minutes in BBS, and then transferred to a solution 
containing the secondary antibody for 2 hours at room temperature. For mouse monoclonal antibodies, a peroxidase-conjugated goat anti-mouse IgG (Jackson Immuno Research Laboratories Inc., West Grove, PA) was used at a dilution of 1:400 in BBS. For sections stained with rabbit polyclonal antiserum, a peroxidase-conjugated donkey anti-rabbit IgG (Jackson Immuno Research Laboratories Inc., West Grove, PA) was used at a dilution of 1:400. The sections were rinsed in 2 changes of $0.2 \mathrm{M} \mathrm{BBS \text {, }}$ followed by three rinses in $0.1 \mathrm{M} \mathrm{PB}(\mathrm{pH}$ 7.2). Then the specimens were incubated in a solution containing $1 \mathrm{mg} / \mathrm{ml}$ of 3, 3 diaminobenzidine tetrahydrochloride (Sigma, St. Louis, MO) in 0.02 M PB (pH 7.4) and $5 \mathrm{ul} / \mathrm{ml}$ of 3\% hydrogen peroxide for 15-30 minutes at room temperature.

\section{Gel Electrophoresis and Immunoblot Method}

Adult Sprague-Dawley rats were anesthetized with a mixture of xylazine $\left(13 \mathrm{mg} / \mathrm{kg}, \operatorname{Rompun}^{\circledR}\right)$ and ketamine $\left(87 \mathrm{mg} / \mathrm{kg}, \operatorname{Ketalar}^{\circledR}\right)$ and then decapitated. The brain of each animal was removed and homogenized in 5 $\mathrm{ml}$ of 0.01 M PBS. Samples of different tissues were dissolved in nonreducing sample buffer (2\% SDS, $10 \%$ glycerol in 0.05 M Tris-HCL buffer, $\mathrm{pH}$ 6.8). These protein samples were separated by sodium dodecyl sulfate polyacrylamide gel electrophoresis (SDS-PAGE) using a 4 to $16 \%$ gradient mini-gel, following procedures described previously (Geisert et al., 1991). After electrophoresis, the proteins were transferred to nitrocellulose using a Bio Rad mini-transblotter. Blots were then blocked in 5\% non-fat dry milk, probed with the AMP1 antibody, anti-GFAP antiserum (Lipshaw, Pittsburgh, PA), or anti-myelin basic protein antiserum (Boheringer Mannheim, Indianapolis, IN). Then the sections were rinsed in borate buffer ( $\mathrm{pH} 8.5$ ), incubated in HRP-labeled secondary antibody and reacted 
with diaminobenzidine and hydrogen peroxide, as previously described (Geisert and Bidanset, 1993). The level of immunoreaction product was determined by scanning the blots and analyzing these scans with the NIH Image Software. To define the relative levels of rTAPA expression, quantification of proteins on immunoblots was conducted using a simple limiting dilution approach. All samples were equilibrated to a set standard using NIH Image Software. The samples were then diluted in two fold increments and run on a 4 to $16 \%$ gradient gel and transferred to nitrocellulose. Immunoblots were stained for rTAPA, using the AMP1 antibody. Blots were scanned into the imaging software using a Macintosh computer with a high resolution desk top scanner (Hewlett Pakard ScanJet II CX). NIH Image software was then used to compare the intensity of the rTAPA immunolabeling to define the dilution factor that produced a similar level of rTAPA immunoreactivity. All samples were standardized to the adult (postnatal day 30 or older animal).

\section{Cell Cultures}

Glial cells were cultured from the cerebral cortex of SpragueDawley rat pups ranging in age from postnatal day 1 (P1) to postnatal day 5 (P5) using a protocol similar to that described in Giesert and Stewart (1991). The animals were anesthetized by cold and decapitated. Immediately following decapitation the brains were removed. The meninges were stripped from the surface, and the cortices were placed in a petri dish containing $10 \mathrm{mls}$ of Hank's Balanced Salt Solution (HBSS). The tissue was placed in $20 \mathrm{mls}$ of $0.1 \%$ trypsin in HBSS for 10 minutes. Then mechanically dissociated and placed in $30 \mathrm{mls}$ of medium containing either $5 \%$ or $10 \%$ fetal calf serum in $75 \mathrm{~cm}^{2}$ flasks at a density of $5 \times 10^{3}$ 
cells $/ \mathrm{cm}^{2}$. The flasks were then placed in an incubator at $37{ }^{\circ} \mathrm{C}$ with $5 \%$ $\mathrm{CO}_{2}$

To define the distribution of rTAPA, the cells were stained using immunohistochemical methods when the cultures were approximately $70 \%$ confluent. The AMP1 antibody was detected with a fluorescein-labeled Goat anti-mouse secondary (Jackson Immunolaboratories Inc., West Grove, PA), to identify rTAPA expression. The cells were counterstained with either a murine monoclonal IgM, directed against oligodendrocytes (Dyer et al., 1991), or a rabbit antiserum directed against GFAP (Lipshaw, Pittsburgh, PA), to identify astrocytes. To facilitate GFAP staining $1 \%$ Triton X-100 was added to the BBS solution. Cultures were washed 3 times for 10 minutes in BBS and then transferred to a solution containing the secondary antibody for 2 hours at room temperature. The secondary antibodies, a rhodamine-conjugated Donkey anti-mouse IgM (Jackson Immunolaboratories Inc., West Grove, PA) or a rhodamine-conjugated Goat anti-rabbit IgG (Jackson Immunolaboratories Inc., West Grove, PA), were used at a dilution of 1:500 in BBS. The cultures were rinsed 3 times for 10 minutes in BBS. The cultures were examined using a Leitz Laborlux D microscope.

\section{In Situ Hybridization}

Three adult Sprague-Dawley rats were perfused as described above, with the exception that all of the solutions were made with DEPC-treated water. The brains were removed, placed in $30 \%$ sucrose, and sectioned at 20 um on a cryostat. Sections were mounted directly onto glass slides and stored at $-20{ }^{\circ} \mathrm{C}$. 
RNA probes were made from a 500 base pair insert placed into the Invitrogen pCR 2.1 vector. The insert encodes for bases $225-725$ of the rTAPA sequence (accession number U19894). Sense and anti-sense cRNA probes were made using the Riboprobe kit from Promega. The probes were synthesized from the linearized plasmid using the T7 and SP6 promoters respectively. The incorporation of digoxigenin (DIG) conjugated UTP was approximately 1 DIG labeled to 4 unlabeled UTP.

Sections were removed from the freezer and placed at room temperature for 30 minutes. Then they were submersed in chloroform for 2 minutes to extract the lipids and the chloroform was allowed to evaporate. The sections were placed in a humidified chamber at $55^{\circ} \mathrm{C}$ for 30 minutes. The probe was prepared by adding $100 \mathrm{ul}$ of the hybridization solution (2X SSC, 10\% dextran sulfate, 2mM EDTA, 50\% deionized formamide, and $200 \mathrm{ug}$ of sperm DNA) to $200 \mathrm{ng} / \mathrm{ml}$ of DIG-labeled probe. The mixture was warmed to $95{ }^{\circ} \mathrm{C}$ for 4 minutes. Labeled probe was then added to the sections and the solution was sealed by applying a coverslip. Care was taken not to trap air under the coverslip. The sections were incubated at $70{ }^{\circ} \mathrm{C}$ for $4-6$ hours. The coverslips were removed by soaking the slides in $2 \mathrm{x}$ SSC overnight at room temperature. The sections were rinsed 3 times at $55^{\circ} \mathrm{C}$ with $50 \%$ deionized formamide in $1 \mathrm{x}$ SSC, 2 times in $1 \mathrm{x}$ SSC at room temperature, and 5 times in TBS pH 7.5 at room temperature. The sections were incubated in the Boerhinger Mannheim blocking solution (Boerhinger Mannheim Indianapolis, IN) for 30 minutes at room temperature. Then an anti-DIG antibody conjugated to alkaline phosphatase (Boerhinger Mannheim Indianapolis, IN) was added to the solution at a 1 to 400 dilution with $1 \%$ blocking solution in TBS pH 7.5 and incubated overnight at $4{ }^{\circ} \mathrm{C}$. The sections were rinsed 4 times for 10 
minutes each with TBS $\mathrm{pH}$ 7.5. The nitro blue tetrazolium chloride and 5bromo-4-chloro-3-indolylphosphate, toluidine-salt (NBT/BCIP) solution was added to the sections and allowed to react for 8-16 hours in the dark at room temperature. 


\section{CHAPTER 3. RESULTS}

In the present study the monoclonal antibody AMP1 was used to define the levels and distribution of rTAPA (CD81). When protein samples were denatured with SDS and presented on nitrocellulose, the AMP1 antibody recognized two proteins. Both proteins were cloned and sequenced (Geisert et al., 1996b). The $106 \mathrm{kDa}$ antigen was alpha actinin and the $27 \mathrm{kDa}$ antigen was rTAPA. Although the AMP1 recognized these two proteins when they are denatured and presented on nitrocellulose, it only recognized rTAPA in formalin fixed tissue or in cultured cells. This is supported by several different lines of evidence (Geisert et al., 1996). Both alpha actinin and rTAPA are found in detergent extracts of rat brain and primary cultures of rat glia; however, the AMP1 antibody will only immunoprecipitate rTAPA, not alpha actinin (Geisert et al., 1996b). Furthermore, the AMP1 antibody recognizes alpha actinin on immunoblots of protein from tissues it will not stain. For example on immunoblots of C6 glioma, human glioma (U737), or human brain, the AMP1 antibody recognizes a single protein at $106 \mathrm{kDa}$ (our antibody does not recognize human TAPA-1). When these glioma or sections of human brain are stained using immunohistochemical methods no immunoreaction product is observed (Data not shown), demonstrating that the antibody can see alpha actinin on immunoblots but not in tissues. Taken together these data demonstrate that the AMP1 antibody recognizes only rTAPA in sections of the rat brain or in cultures of rat cells under the conditions that we employed.

The relative levels and distribution of rTAPA in different tissues were examined using immunoblot methods. Protein samples were taken 
from a number of different rat tissues: liver, muscle, tendon, kidney, testicle, cartilage, skin, sciatic nerve, and brain. These protein samples were equilibrated and placed in non-reducing sample buffer. The highest levels of rTAPA were found in the protein samples of brain, with detectable levels observed in the protein samples of cartilage, testicle, and kidney (Fig. 1). The remaining tissues had minimal levels of rTAPA, including the sample of peripheral nerve (Fig. 1 lane G). The relative levels of rTAPA in the brain and kidney were compared by a limiting dilution analysis. Approximately equivalent levels of rTAPA were found when the full strength sample of kidney proteins was compared to the sample of the brain diluted 1 to 64 . These data demonstrated the high levels of rTAPA in the brain, especially in comparison to the other body tissues examined.

\section{Developmental Regulation of rTAPA in the Brain}

The developmental expression pattern of rTAPA in the developing brain was quantified using immunoblot methods. To allow for the quantitative immunoblot analysis of rTAPA, protein samples from different developmental stages were made (Fig. 1 lanes A and B). Protein samples were taken from embryonic day 18 (E18, the time of peak neuronal birth in the cerebral cortex), postnatal day 1 (P1, near the end of neurogenesis and the beginning of gliogenesis), P7 (a time near the peak of gliogenesis), P14 (a time of rapid glial maturation) and P30 (when the brain is relatively mature). All samples were equilibrated and the levels of rTAPA within each sample were determined by running samples of two different ages on the same immunoblot. The levels of rTAPA observed in the adult samples were set at $100 \%$ and three independent samples were taken at each time point (Fig. 2). The levels of rTAPA observed at E18 and P0 were similar 


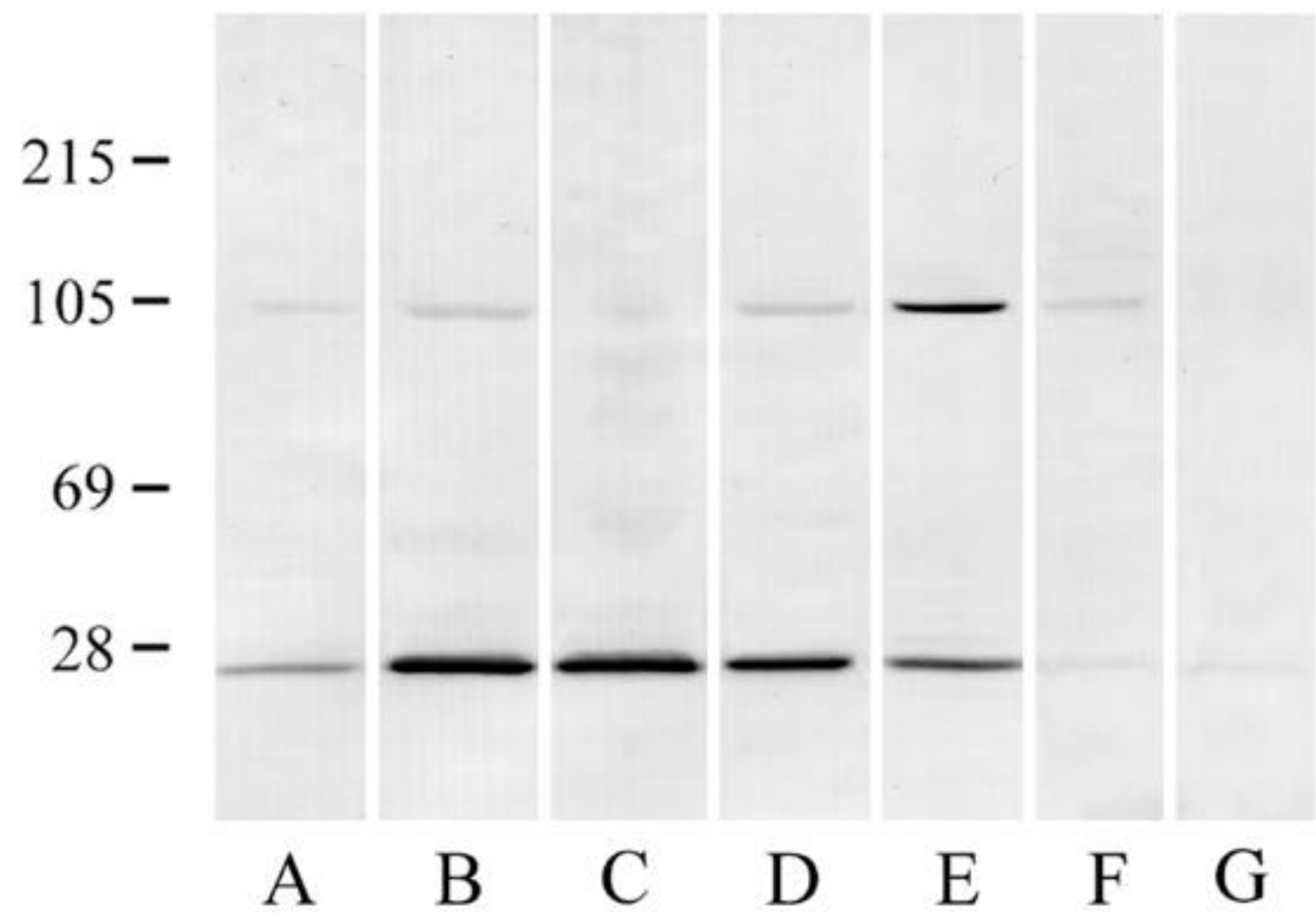

Figure 1 Blots of protein samples from different rat tissues were stained with the AMP1 antibody. Under non-reducing conditions, the AMP1 antibody recognizes two proteins when they are presented on nitrocellulose: alpha actinin at $106 \mathrm{kDa}$ and rTAPA at $26 \mathrm{kDa}$. Six different rat protein samples are shown: E18 brain (A); adult brain (B); dissected subcortical white matter from the adult $(\mathrm{C})$; gray matter from the adult cerebral cortex (D); a sample of cultured astrocytes (E); kidney (F); and peripheral nerve $(G)$. The total load of proteins in all lanes were balanced. Notice that the levels of rTAPA in the adult brain are considerably higher than that observed in the kidney, the embryonic brain, and peripheral nerve. In addition, the levels of rTAPA in the white matter are approximately equal to that found in the gray matter. Molecular weight markers are indicated to the left in kilodaltons. 
and represented approximately $7 \%$ of the adult. The most dramatic upregulation of rTAPA occurred in the second postnatal week, increasing from $15 \%$ of adult at P7 to $70 \%$ by P14. Following P14 there was a gradual increase until adult levels were reached.

Since the increase in the levels of rTAPA appeared to correlate with the birth and maturation of glial cells, we examined the protein levels associated with astrocyte and oligodendrocyte maturation. As astrocyte mature there is a switch from the intermediate filament protein vimentin to GFAP. Thus, these two proteins were used as markers for the maturation of astrocytes. Immunoblots of protein samples from the developing brain were probed with antibodies directed against GFAP and vimentin (Fig. 3). As expected the levels of vimentin decreased as the levels of GFAP increased. This increase in GFAP and decrease in vimentin occurs with approximately the same time course as the upregulation of rTAPA. The second major class of macroglia is the oligodendrocytes. Myelin basic protein was used as a marker for mature oligodendrocytes and myelin (Fig 3). The upregulation of myelin basic protein was delayed relative to that of rTAPA. Myelin basic protein was not observed until P14. A dramatic increase in the levels of myelin basic protein occurred between P14 and P30. These immunoblot data indicate that rTAPA is upregulated along a time course that is similar to that of other proteins associated with glial maturation.

\section{Cellular Distribution of rTAPA:}

Our immunoblot analysis indicates that rTAPA is expressed during the maturation of glia within the brain and that very low levels of the protein are found before this developmental period. Two different 


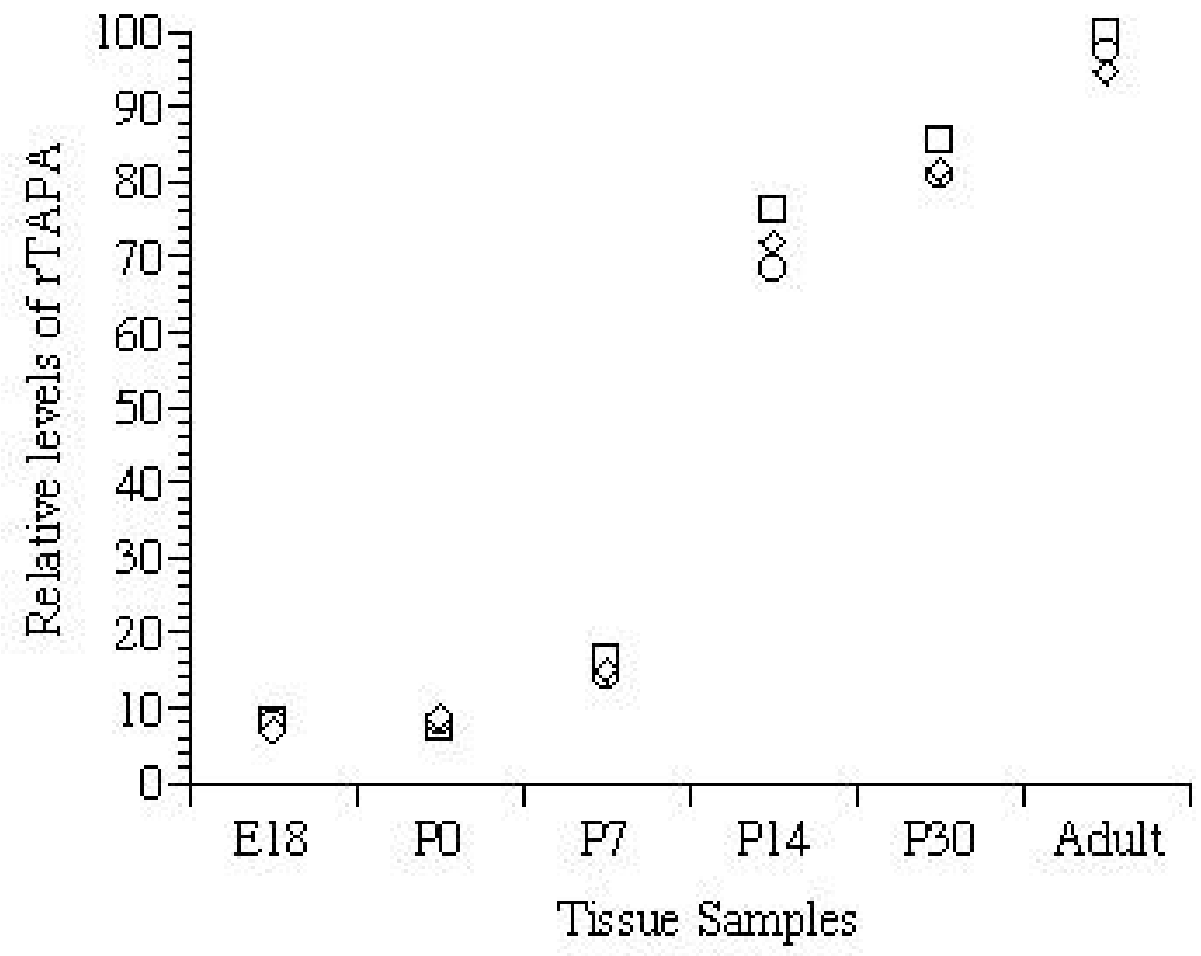

Figure 2 The levels of rTAPA at different developmental ages are shown. Limiting dilutions of samples containing equivalent amounts of protein were used to define the relative amounts of rTAPA, expressed as a percentage of adult. Through postnatal day 7 the expression levels of rTAPA remain low, under $15 \%$. By postnatal day 14 a dramatic increase in expression is seen with $70 \%$ of adult expression observed. The change in expression between P7 and P14 is statistically different (Mann-Whitney U test, $\mathrm{p}<0.05)$. Notice that the levels of rTAPA continue to increase even after P30. 


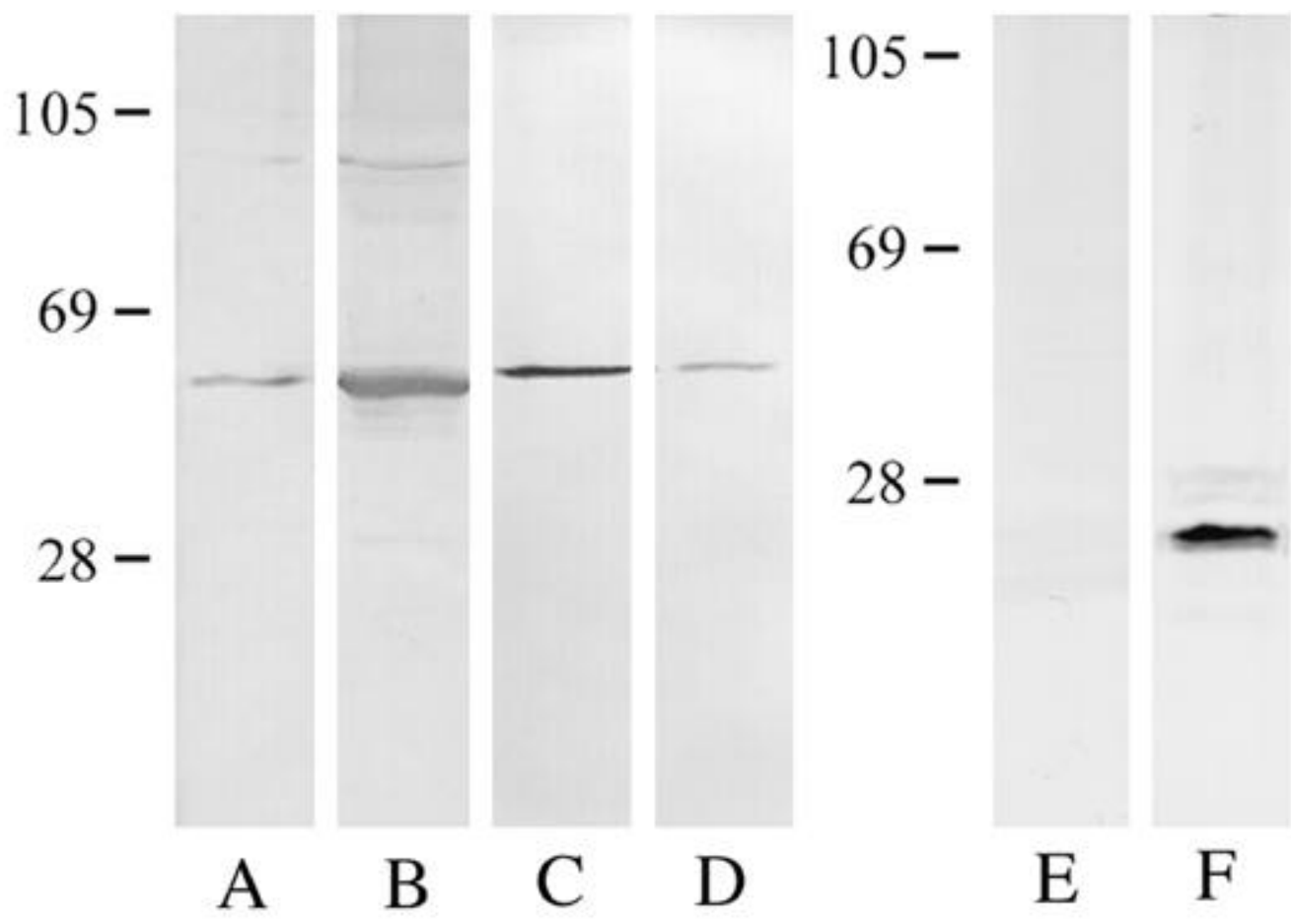

Figure 3 The developmental regulation of specific astrocyte and oligodendrocyte marker proteins were examined using immunoblot analysis. Whole brain protein samples of $\mathrm{P0}$ (lanes A, C, and E) and P30 (lanes B, D, and F) rats were blotted and probed with antibodies to GFAP (lanes A and B), vimentin (lanes C and D), and myelin basic protein (lanes $\mathrm{E}$ and $\mathrm{F}$ ). The expression of GFAP is dramatically upregulated from P0 to P30, while vimentin expression is greatly reduced. Myelin basic protein shows no expression at $\mathrm{P} 0$ but is highly expressed at P30. approaches were taken to define the cells within the brain that express this protein. 
The first was to examine cultured cells using immunohistochemical methods and the second was to use in situ hybridization to define the cells containing the messanger ribonucleic acid for rTAPA. Neurons and glia were cultured from the developing rat CNS and stained by immunohistochemical methods using the AMP1 antibody. The cell cultures were counterstained to define astrocytes (using anti-GFAP antiserum), oligodendrocytes (using the CE1 monoclonal antibody) or neurons (using the TuJ1 antibody). AMP1 stained astrocytes and oligodendrocytes (Fig. 4). The rTAPA immunoreaction product was seen primarily at points of cell-cell contact for both type 1 astrocytes and type 2 astrocytes. Oligodendrocytes were more intensely stained by AMP1 than astrocytes. High density staining was seen throughout the cells, with staining extending to the tips of all processes. AMP1 immunostaining was not seen on the TuJ1 positive neurons (data not shown). These data demonstrated that both cultured astrocytes and cultured oligodendrocytes express rTAPA.

\section{In Situ Hybridization}

One approach to defining the cells within the adult brain that express rTAPA is to use in situ hybridization. Figure 5 illustrates the pattern of labeling in the hippocampus following hybridization with the sense probe (Fig 5A and 5C) and the antisense probe (Fig. 5B and 5D). When comparing the antisense labeling to the sense labeling a clear pattern of cellular labeling is observed. The most dramatic difference is in the many small cell bodies throughout the sections labeled with the antisense probe. In addition, the choroid plexus is heavily labeled along 

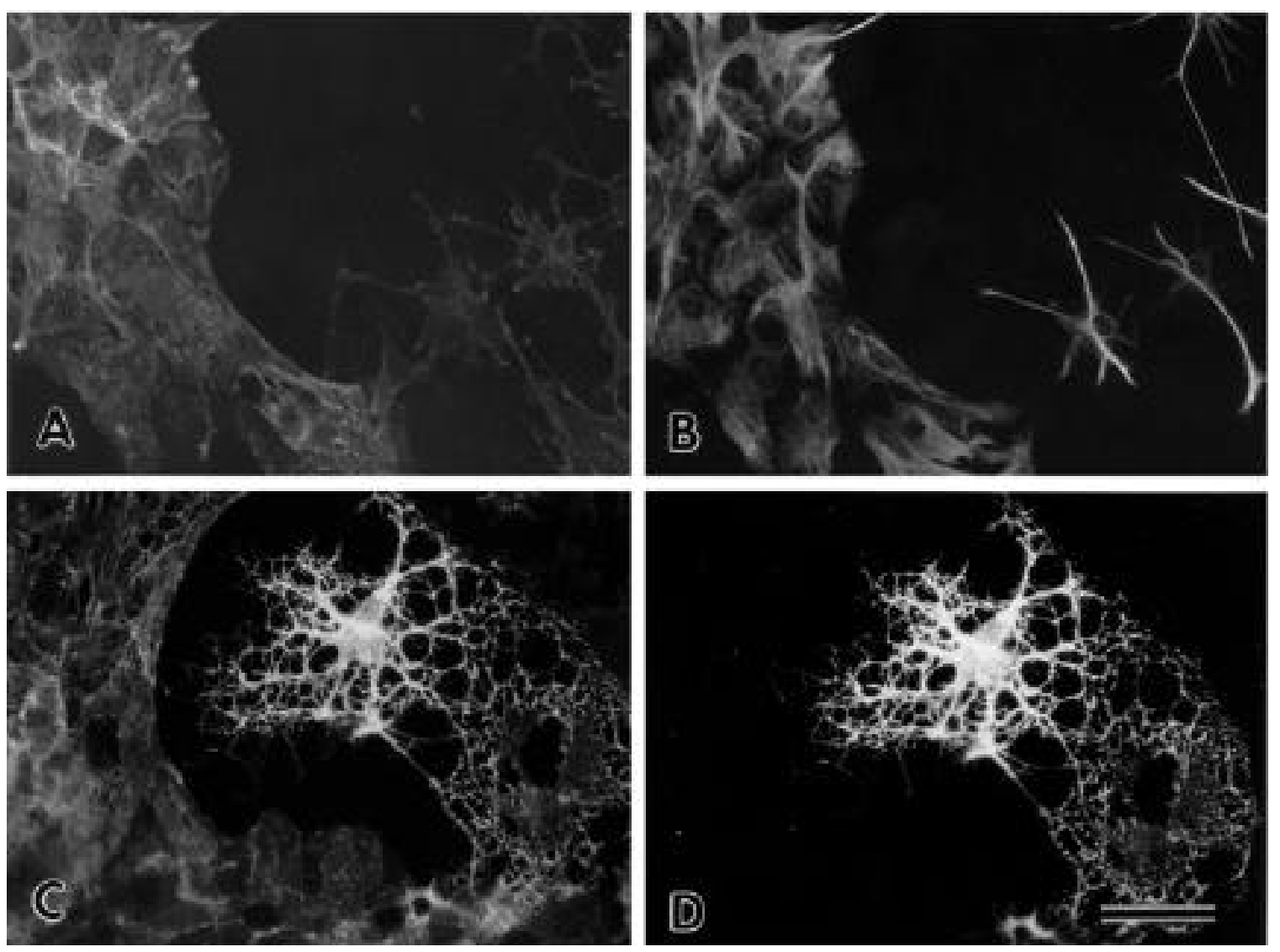

Figure 4 The pattern of AMP1 labeling is illustrated in photomicrographs of mixed glial cultures. The cultures were stained with AMP1 (A and C). Panel A and B are taken from the same culture, counterstained with antiGFAP (B), to mark astrocytes. Panel C and D are taken from the same culture, counterstained with the CE1 antibody (D), to mark oligodendrocytes. The AMP1 antibody labels the external surface of both astrocytes and oligodendrocytes. All photomicrographs taken at the same magnification. Scale bar $=50 \mu \mathrm{m}$. 

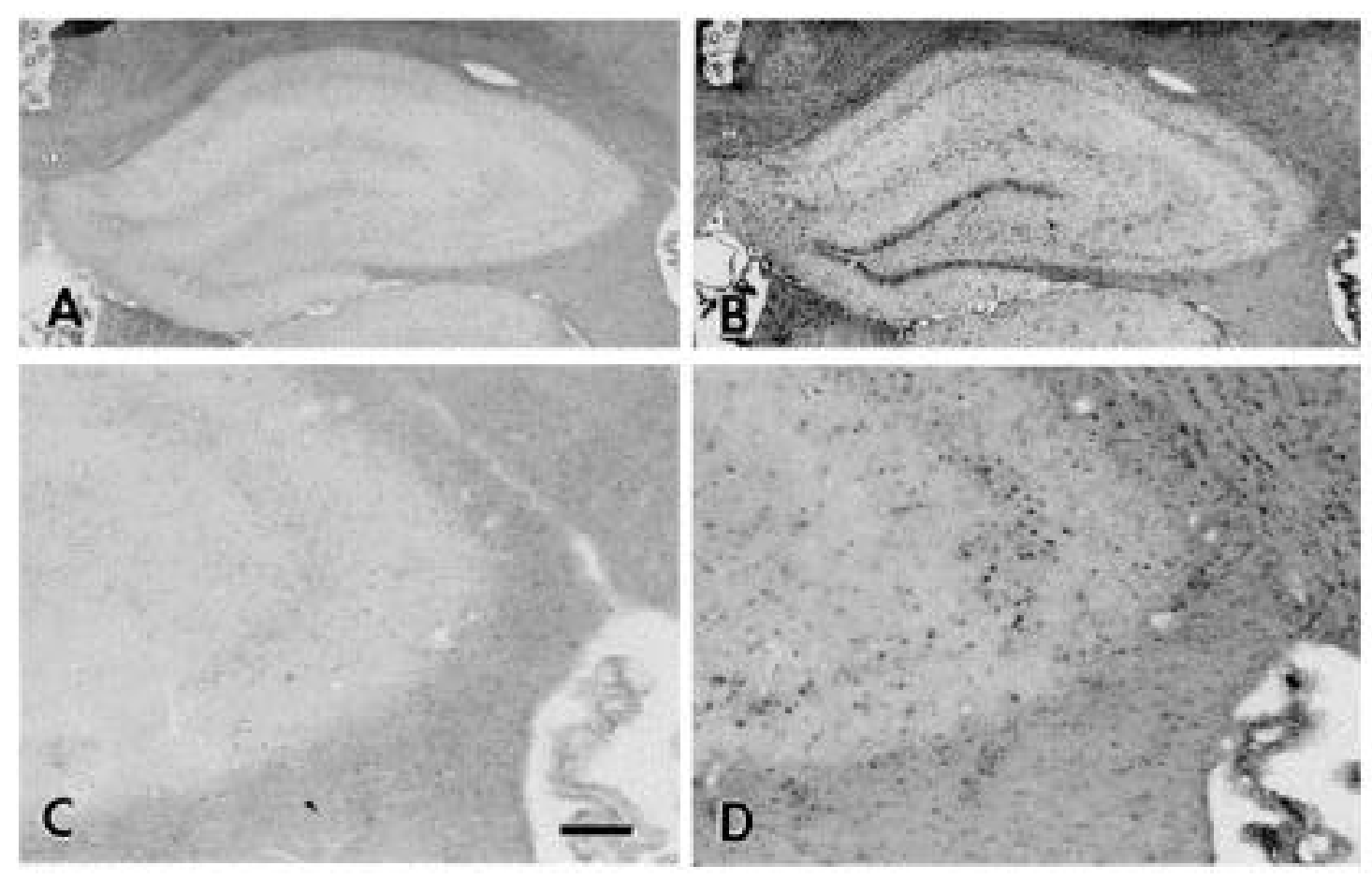

Figure 5 The cells expressing rTAPA mRNA are illustrated by using in situ hybridization. A and B are low magnification photomicrographs of the hippocampus from adjacent sections of the adult rat brain. C and D are higher magnification photomicrographs taken from the CA3/alveus region. The section illustrated in $\mathrm{A}$ and $\mathrm{C}$ was probed with the sense riboprobe and the section in B and D were labeled with the antisense riboprobe. At the low magnification, the general pattern of labeling can be observed. Notice that the choroid plexus and ependymal lining of the ventricles are heavily labeled. At a high magnification, many cell bodies are labeled with the antisense probe and there is a lack of labeling in the pyramidal cell layer. The Scale bar in C = $100 \mathrm{um}$. 
with the ependymal lining of the ventricles. A closer examination of the tissues reveals that the large pyramidal cells of the hippocampus are not labeled (Fig. 5B and 5D). In these sections, no labeling of large identifiable neurons was observed. The labeling of small cell bodies within the gray matter and white matter is consistent with the expression of rTAPA by glia within the CNS.

\section{Distribution of rTAPA in the Developing Brain}

To define the distribution of rTAPA during the development of the CNS, we examined sections through the brain using indirect immunohistochemical methods. This analysis included coronal sections from a variety of developmental stages: E18, P0, P7, P14, P30 and adult. In the E18 brain, low levels of the AMP1 immunoreaction product were observed within the parenchyma of the brain, with virtually no labeling of the neocortex or neostriatum (data not shown). The most notable accumulation of immunoreaction product was observed in the choroid plexus and the ependymal lining of the ventricular system. There was also a pronounced labeling of the glia limitans. AMP1 labeling patterns in the P0 brain are illustrated in figure 6B. Since the blood brain barrier is not formed at this age it was important to compare the pattern and intensity of labelling observed in the AMP1 stained sections to those found in similar control sections treated in an identical manner with the exception that the primary antibody was omitted from the staining protocol. The secondary antibody was preabsorbed against rat $\mathrm{IgG}$, and the immunoreaction product in the control section was minimal (Fig. 6A). There was a modest 

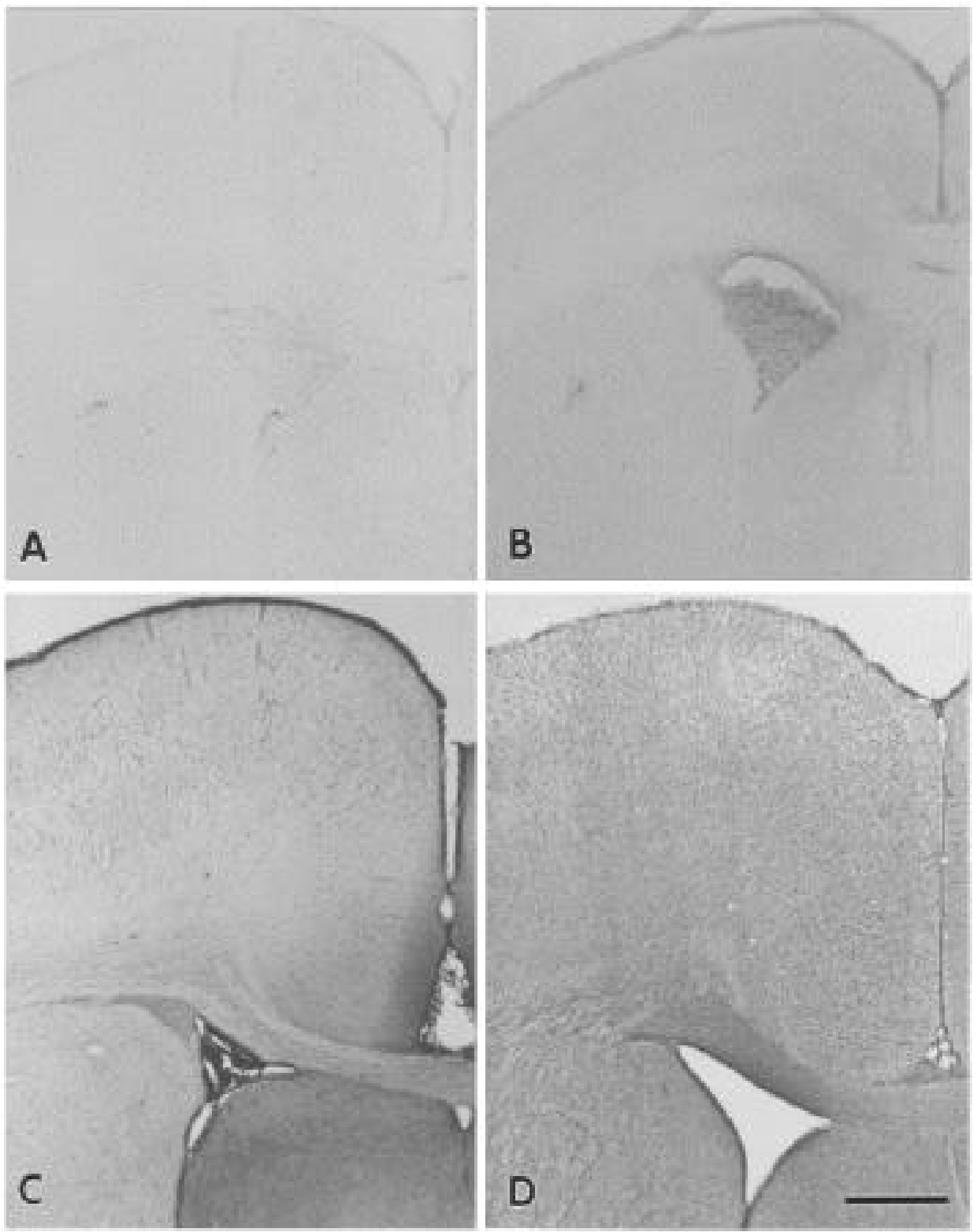
Figure 6 The distribution of AMP1 immunoreactivity in the rat brain is illustrated at three different developmental ages. A and B are sections from a $\mathrm{P} 0$ rat brain. $\mathrm{C}$ is a section from a $\mathrm{P} 14$ rat brain. $\mathrm{D}$ is a coronal section from an adult brain. A is a control section stained in a manner identical to that of B with the exception that the primary antibody was omitted. Notice that there is minimal staining with the secondary antibody alone. In B the immunolabeling pattern of the AMP1 antibody is shown. The most dramatic labeling is seen in the choroid plexus and glial limitans. As the brain matures the levels of immunoreactivity are dramatically upregulated, as can be seen in the section from the P14 brain (C). The highest levels are found in the adult (D). All photomicrographs are taken at the same magnification. The scale bar in $\mathrm{D}=500 \mu \mathrm{m}$. 
amount of labeling at the edge of the section and in the choroid plexus. When the section stained with the AMP1 antibody was compared to this control section, a substantial amount of antibody-specific staining was observed. The most heavily labeled structures were the choroid plexus and the ependymal cells lining the lateral ventricle. Relatively high AMP1 immunoreactivity was also observed at the glia limitans. This labeling appeared to be specific to the AMP1 antibody since the individual cellular processes could be observed and this type of labeling was not seen in the control section. Along with these high levels of reaction product, there was also a modest amount of diffuse labeling in the parenchyma of the brain. The levels of AMP1 immunoreactivity in the parenchyma slowly increased over the next several weeks.

Although the overall levels of AMP1 immunoreactivity increased between P7 and P14, the general pattern of expression was similar. Therefore, only the AMP1 immunoreactivity observed at P14 is illustrated(Fig. 6C). In sections stained with the AMP1 antibody, there was an increase in immunoreactivity throughout the brain during this period. The highest density of staining was seen in the glial limitans, choroid plexus, and ependymal lining of the ventricular system. In these structures there were indications that rTAPA was concentrated at specific regions of the cells. The best example of this was the choroid plexus. At high magnifications, immunoreaction product was concentrated at regions of cell-cell contact (Fig. 7A), reminiscent of the staining pattern observed in confluent cultures of type 1 astrocytes. This labeling outlined the individual choroidal cells giving the appearance of a tiled mosaic. A similar type of cellular distribution and patterning was also seen in the ependymal 


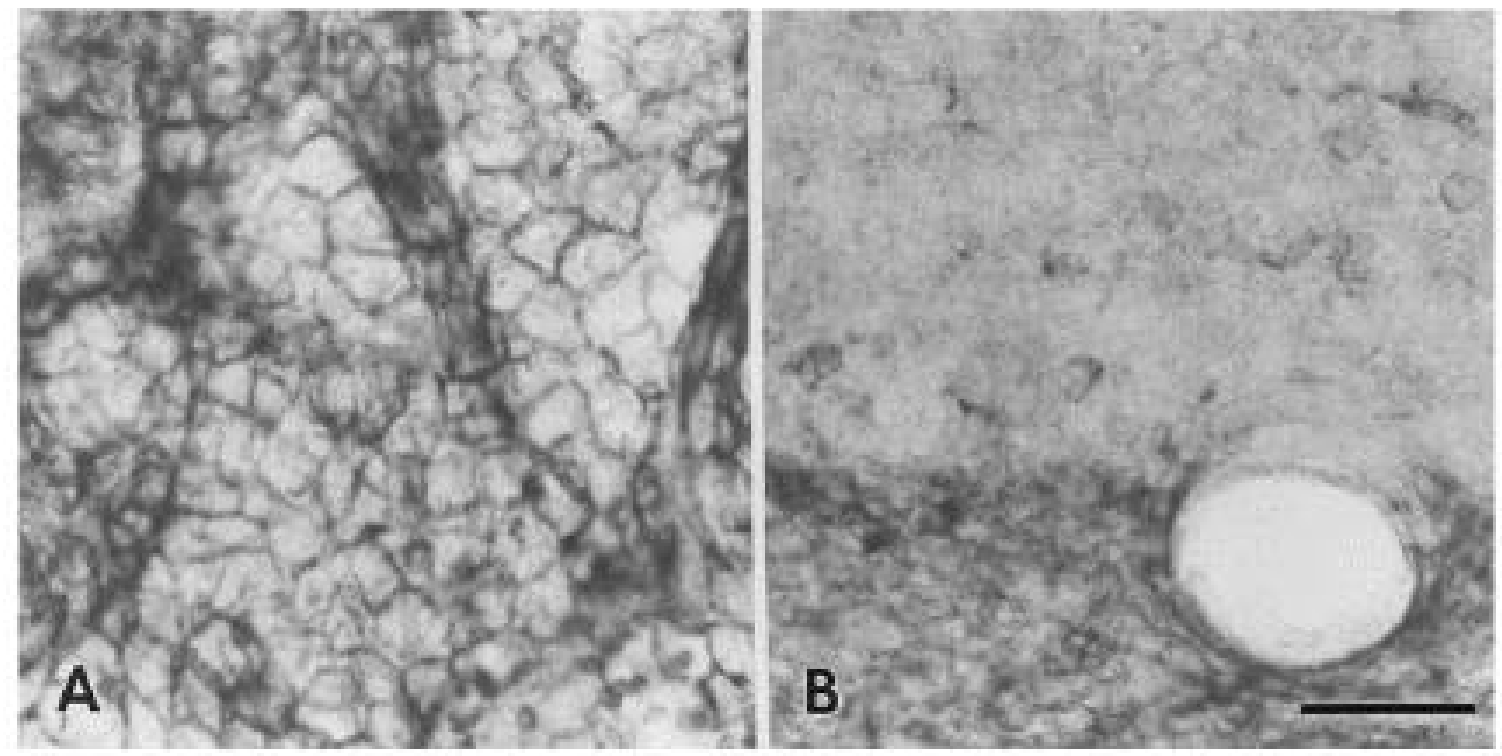

Figure 7 The pattern of immunolabeling in the choroid plexus (A) and the junction between white and gray matter (B) can be seen in these high magnification photomicrographs taken from the P14 brain. The choroid plexus illustrates the high levels of rTAPA immunoreactivity at the sites of cell-cell contact. Note the difference in the staining pattern at the junction between the white and gray matter, along with the staining of small cell bodies with AMP1 (B). Both photomicrographs are taken at the same magnifications (Scale bar in $B=50 \mu \mathrm{m}$ ). 
lining of the ventricular system (data not shown). Finally, an increase in immunoreactivity was observed surrounding all blood vessels (Fig. 7B). In these young animals, immunoreaction product outlined small cell bodies in the gray and white matter.

\section{Distribution of rTAPA in the Adult Brain}

When tissue sections of the adult brain were stained with the AMP1 antibody, a reticulated pattern of labeling was seen throughout the tissue, with clear evidence of specific concentrations of immunoreaction product (Fig. 6D). The regions with elevated levels of immunolabel were all associated with glial structures. At the glia limitans, there was an elevation of labeling just beneath the pial surface. High levels of AMP1 labeling were also observed at the ventricular surface, where rTAPA was seen to concentrate at regions of cellular contact between and beneath the ependymal cells. Similar to the ependyma, the choroid plexus also displayed intense AMP1 immunoreactivity. If the choroidal cells were examined face on, the pattern of labeling exquisitely marked the junctional regions between cells, leaving a mosaic pattern of staining. In the gray and white matter of the adult brain it was difficult to identify the types of cells carrying the immunoreaction product. In the gray matter a dense irregular reticulated pattern of labeling was seen with little indication of neuronal labeling. The pattern observed in the white matter differed, with a regular linear array to the staining pattern. The orientation of this linear array mimicked the direction of axonal pathways within the section of white matter. The pattern of labeling in the adult brain was consistent with a generalized staining of glial processes. 
When sections through the adult spinal cord were stained with AMP1 (Fig. 8C), the general pattern of immunoreactivity was similar to that observed in sections stained with the astrocyte marker GFAP (Fig. 8A). The intensity of labeling in the gray matter was heavier than that of the white matter where bundles of axons were running up and down the spinal cord. Similar to the brain, there was a general increase in labeling at the glial limitans. There were also elevated levels of GFAP and AMP1 immunoreactivity around the central canal. The most intriguing similarity between these two sections was the staining of the trabecular network of astrocytic processes by GFAP and the similarly stained pattern in the AMP1 sections. This was particularly evident at high magnifications, where the pattern of GFAP-positive processes (Fig. 8B) was very similar to that found in the AMP1 stained section (Fig. 8D).

Interestingly, there were no indications that compact myelin was labeled with AMP1 antibody in these sections of the spinal cord. This appeared to contradict data from tissue culture studies, where the AMP1 antibody stained both astrocytes and oligodendrocytes. To provide an independent means of assessing the distribution of rTAPA, samples of total brain, gray matter, white matter and myelin were analyzed using a quantitative immunoblot method. This approach revealed that rTAPA was found at approximately equal levels in gray matter, white matter and myelin (Fig. 3). Therefore, rTAPA is in compact myelin and appears to be expressed by all glial cells. Although there are a number of possible explanations for the lack of immunostaining of compact myelin, the most likely explanation is that the extracellular epitope is hidden within the wraps of compact myelin. 


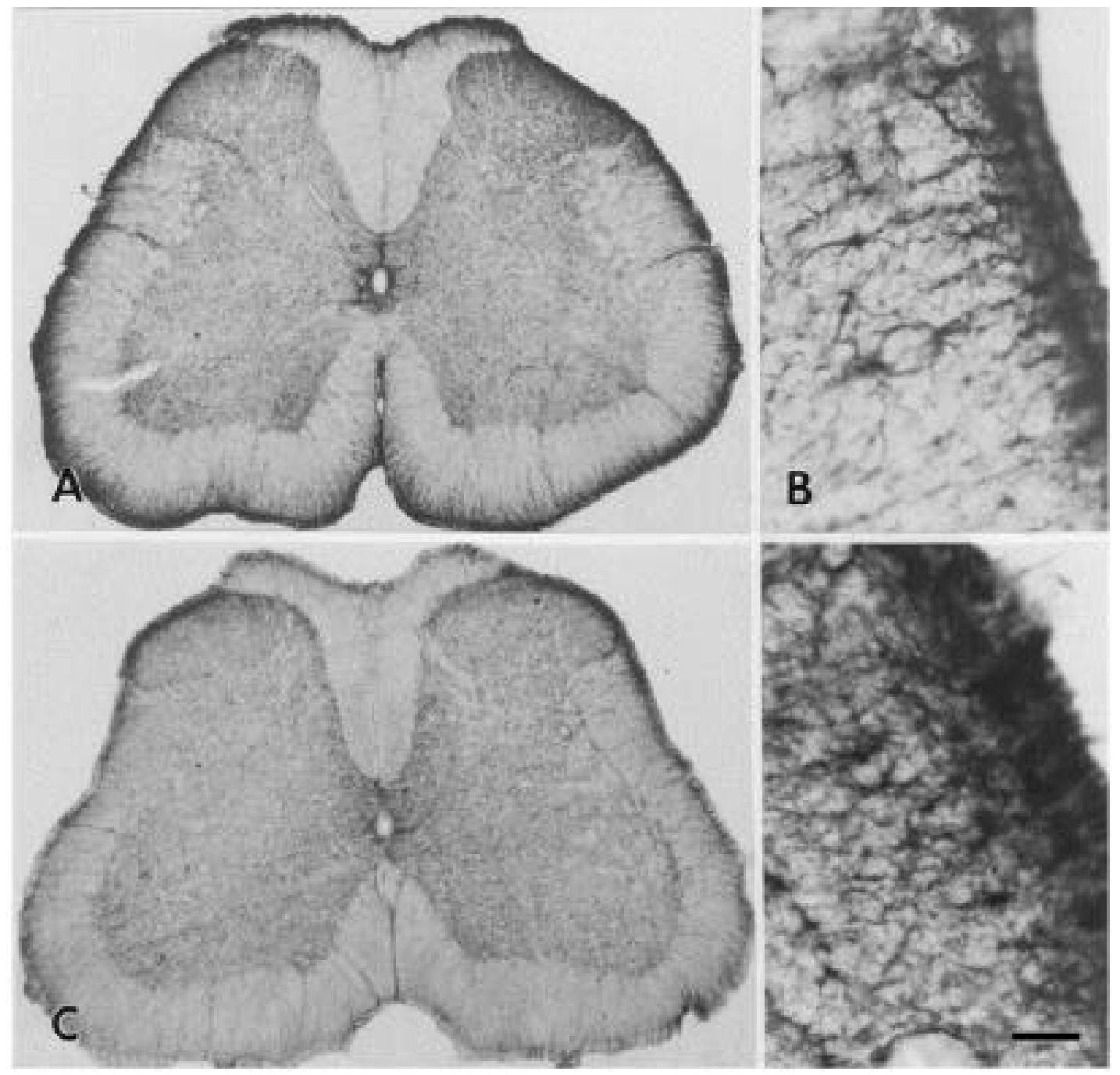

Figure 8 The distribution of AMP1 immunoreactivity in the adult spinal cord is illustrated in a series of low and high magnification photomicrographs. High levels of AMP1 immunoreactivity (C and D) are observed in the spinal cord. In a similar section stained for GFAP (A and B), the distribution of astrocytes in the spinal cord is illustrated. As in cortex, the AMP1 immunoreactivity in white matter is lower than gray matter (C). Note the similarity in the staining patterns between the antiGFAP and AMP1 stained sections. A and $\mathrm{C}$ are at the same magnification and $\mathrm{B}$ and $\mathrm{D}$ are higher magnification photomicrographs (Scale bar in $\mathrm{D}=$ $25 \mu \mathrm{m})$. 


\section{CHAPTER 4. DISCUSSION}

The present study examines the expression of rTAPA in the developing rat brain and spinal cord. The immunoblot analysis reveals three distinct phases in regulation of rTAPA within the brain. Before the second postnatal week the levels of rTAPA are relatively low. Then there is a dramatic upregulation of the protein during the second postnatal week. During the last phase, the levels of rTAPA continue to increase gradually until adult levels are reached. In addition to the overall change in the levels of rTAPA, there is a striking alteration in the distribution of the protein. The relatively low levels of rTAPA observed in the embryonic brain are associated with the glial limitans, the ependymal lining of the ventricular system, and the choroid plexus. This pattern of rTAPA expression remains relatively constant from E18 through the first postnatal week. During this developmental period most of the neurons within the brain are born and are entering their final stages of development (Berry and Rogers, 1965). The low levels of rTAPA and the lack of detectable neuronal labeling in the brain or spinal cord demonstrates that rTAPA is not directly involved in this phase of neuronal development. The labeling observed at the glia limitans, the ependymal lining of the ventricle and the choroid plexus, indicates that rTAPA is specifically involved with these glial cells.

During the second postnatal week there is a dramatic increase in the overall levels of rTAPA. The relative levels go from $15 \%$ of adult at P7 to $70 \%$ of the adult level by P14. As observed at earlier stages of development, the ependymal cells, the choroid plexus and glial limitans are labeled by the antibody. The predominant change in the distribution of 
the protein occurs within the parenchyma of the brain and spinal cord. A fine reticulated pattern of immunoreaction product is found through the tissue with labeling of small cell bodies. The labeling of these small cell bodies may reflect the birth and maturation of glia. The maturation of these glial cells makes the second postnatal week a very interesting developmental period, characterized by dramatic changes in proteins related to the glial environment. One indicative change in maturing astrocytes is a change in intermediate filament proteins. The cells downregulate vimentin as GFAP expression increases (Dahl, 1981). It is also during this period that astrocytes acquire the ability to become reactive and to form a glial scar. It is during this period that oligodendrocytes are also born and begin to form myelin. Oligodendrocytes express a number of unique and well characterized proteins involved in the formation of myelin (Raff et al., 1978; Raff et al., 1979; Reynolds and Wilkin, 1988; Hardy and Reynolds, 1991; Miller, 1996). One of these proteins, myelin basic protein, is expressed by mature oligodendrocytes and compact myelin. We have found that rTAPA levels increase dramatically at a time when both astrocytes and oligodendrocytes are born and begin to mature. These data indicate that rTAPA upregulation is associated with these cell types. This is supported by the evidence from tissue culture, where both astrocytes and oligodendrocytes are labeled by the AMP1 antibody.

After the second postnatal week there is a gradual increase in the levels of rTAPA. During this period the levels of rTAPA within the parenchyma of the brain appear to increase. In white matter tracts a fine linear array of immunolabeling is observed and there is very little indication of staining within compact myelin. One of the key developmental events 
occurring during these last phases of development is the myelination of axons by oligodendrocytes. Since immunoreactivity in compact myelin was not observed, biochemical methods were used to asses the levels of rTAPA in myelin sheaths. This analysis of myelin isolated from adult brain demonstrated that rTAPA is present in myelin at levels equivalent to that of the white matter or gray matter. To address the time frame of rTAPA expression relative to myelin production, the temporal expression of myelin basic protein was defined. At P7 myelin basic protein was not detectable by immunoblot methods, and only moderate levels were observed by P14. At the next time point examined, P30, near adult levels were observed. These results are consistent with the observations of Hardy and Reynolds (1991) and LeVine and Goldman (1988), who found mature oligodendrocytes around P10 but very few at P7. The gradual increase in rTAPA expression in the later phases of development appears to be attributed to the late maturation of oligodendrocytes and compact myelin.

\section{Cells Expressing rTAPA}

Within the brain and spinal cord a variety of cell types express rTAPA. The first cells to express it are ependymal cells and choroidal cells. These cells are clearly labeled at E18 and remain labeled in the adult animal. The dramatic upregulation of rTAPA during the second postnatal week appears to be associated with the expression of this protein by astrocytes and oligodendrocytes. This is substantiated by tissue culture experiments in which both astrocytes and oligodendrocytes were labeled by an antibody directed against rTAPA. The last major class of glia are microglia (Flaris et al., 1993). Finally, the potential expression of rTAPA by neurons is more difficult to assess. In the embryonic and early postnatal 
brain, neurons do not appear to express rTAPA, for there is no labeling of the parenchyma of the brain. Once the fine reticulated pattern of labeling appears in the gray and white matter, it is very difficult to define which of

the cell types are labeled by the AMP1 antibody. To determine if neurons in the adult brain express rTAPA, in situ hybridization was used. In these experiments the only cells that were labeled by the antisense rTAPA probe had small cell bodies and no clear neuronal labeling was observed. This lack of neuronal labeling was particularly clear for the pyramidal cells of the hippocampus and the cerebral cortex, where the large cell bodies could be seen and these cells were not labeled. Even though neuronal labeling was not observed, the possibility that some population of neurons expresses rTAPA cannot be excluded. Taken together these data demonstrate that rTAPA is expressed by glial cells during a postnatal period of astrocyte and oligodendrocyte maturation.

\section{Astrocyte Maturation}

Astrocytes have many different functional roles in the CNS. During the development of the brain and spinal cord, astrocytes are involved in the migration of neurons from germinal zones to their final locations (Hatten, 1990; Anton et al., 1996). In addition, interactions between astrocytes and growth cones are thought to be critical to the formation of neuronal pathways (Silver and Rutishauser, 1984). Later in development, specific sets of astrocytes in boundary regions express proteins believed to separate functional units of the CNS (Steindler et al., 1990; Geisert and Bidanset, 1993). As development continues, astrocytes appear to take over a role of maintaining a homeostatic environment within the CNS and forming protective barriers (Walz and Hertz, 1982; Ballanyi et al., 1987). 
Astrocytic endfeet at the edge of the brain provide one of the key structural components of the glial limitans. Astrocyte contact with endothelial cells induces the formation of the blood-brain barrier. Astrocytes aid in the regulation of ionic and molecular compounds in the extracellular fluids through specific uptake mechanisms. The astrocytic barriers are located at each point of contact between the CNS and the outside world. In addition, during the final stages of development, astrocytes are believed to be directly involved in stabilization of CNS structure and synaptic connectivity patterns. It is during this final stage of development that astrocytes acquire the ability to respond to injury and become reactive (Berry et al., 1983) and aquire macrophage-like features (Fontana et al., 1984; Takiguchi and Frelinger, 1986). Part of the response to injury may be the expression of major histocompatibility II proteins which can associate with human TAPA-1 in the plane of the cell membrane (Secrist et al., 1996). During this period of development there is a tight correlation between upregulation of rTAPA at the site of injury and the ability of astrocytes to become reactive as judged by GFAP staining (Geisert, personal observation).

\section{Role of rTAPA}

In several cases the molecular interactions of the tetramembrane spanning family members have been defined. Some family members interact with traditional adhesion molecules. For example, CD9 is associated with $\beta 1$ integrins (Slupsky et al., 1989; Masellis-Smith and Shaw, 1994). On the other hand, some of the tetramembrane spanning family members are associated with either kinase or phosphatase activity. These associations appear to link cell adhesion to second messenger 
systems. These molecular cascades affect cell behaviors such as mitotic activity and cell adhesion (Nakamura et al., 1995). For example, during platelet activation (Jennings et al., 1990; Yatomi et al., 1993) there is an increase in phosphorylation that can be replicated by the binding of the CD9 antibody. Similar effects are observed with TAPA-1, where antibody binding activates a tyrosine kinase (Schick et al., 1993). Finally, late bloomer appears to be associated with adhesion at the neuromuscular junction and phosphatase activity (Kopczynski et al., 1996).

Like other members of this family of proteins, an analysis of the deduced structure of rTAPA (fig. 9) reveals that a large part of the molecule is found within the cell membrane, with four transmembrane domains accounting for approximately $40 \%$ of the structure. It also exhibits a large and small extracellular loop. Assuming that the cystines at amino acid 156 and 190 of the large extracellular loop are linked by a disulfide bond, both loops would be closely associated with the cell membrane. Furthermore, based on a secondary structural analysis using predictions from Chou and Fasman, 1974, and Garnier et al., 1978, the loop forms an alpha helix. Since each amino acid in an alpha helix represents a distance of $1.5 \AA$, the maximum distance the large loop can extend from the surface of the cell is $40.5 \AA$. Even if no disulfide bonds are formed the maximum distance the second loop can extend from the surface of the cell is $64.5 \AA$. Based on X-ray crystallographic studies of N-cadherin (Shapiro et al., 1995), a cell adhesion molecule, the extracellular space is approximately $290 \AA$ from membrane to membrane. Thus, the two 


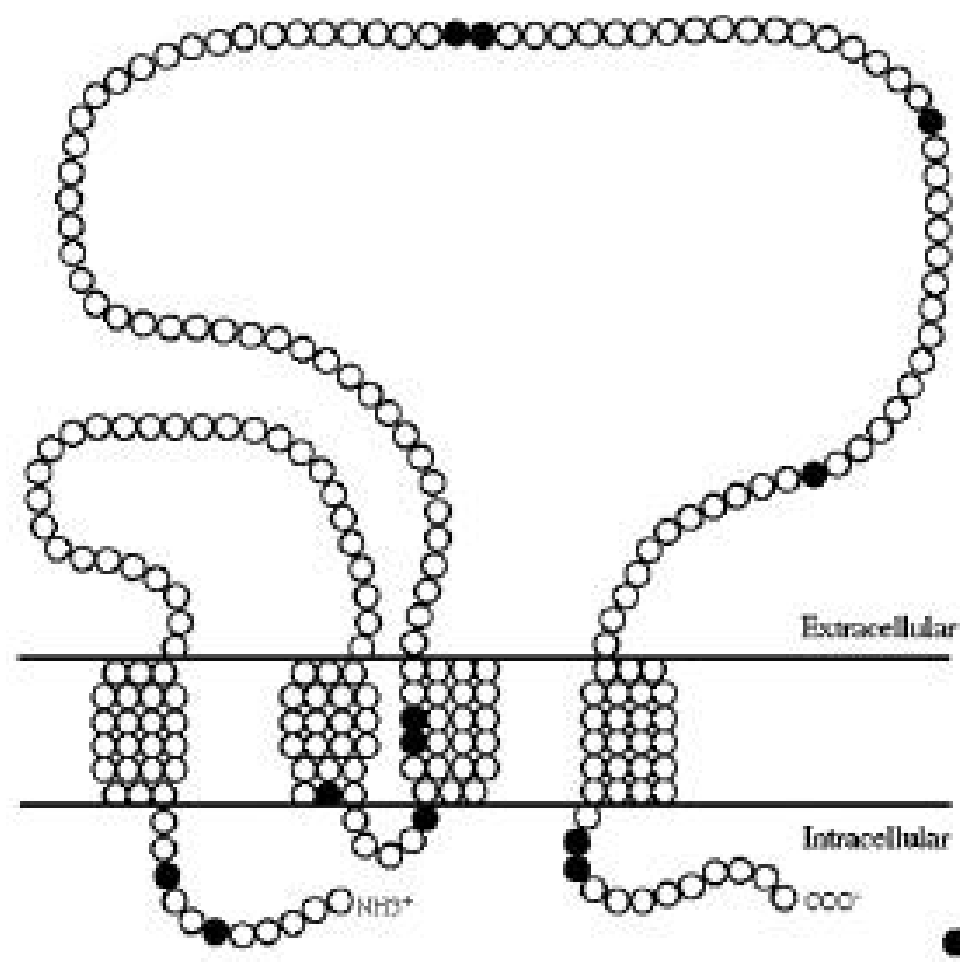

= Cystrine

MGVEGCTKCIKYLLFVENFVFWLAGGVILGVALWLRHDPQTTTLLYL 47 ELGDKP APSTFYVGIYILIAVGAVMMFVGFLGCY GAIQESQCLLGTFF 95

TCLVILFACEVAAGIWGFVNKDQIAKDVKQFYDQALQQAVMDDDANN 142 AKAVVKTFHETLMCCGSNTLTTLTTAVLRNSLCPSSSMSFTQLLKED 189

CHQKIDELF SGKLYLIGIAAIVVAVIMIFBMILSMVLCCGIRNSSVY 236

Figure 9 The structure of rTAPA is illustrated in the upper portion of the figure. It possesses a large and small extracellular loop, with intracellular amino and carboxy termini. Notice that the large extracellular loop has four cystines which may form disulfide bonds sensitive to reducing reagents. This may explain the destruction of the AMP1 epitope following sample reduction. In addition to this model of rTAPA, the deduced amino acid sequence of the protein is shown. The membrane spanning regions were defined using hydrophobicity analysis and these portions of the protein are underlined. 
extracellular domains of the molecule appear to be too small for direct interactions across the extracellular space.

Antibodies directed against the human hematolymphoid cell protein TAPA-1 cause an increase in adhesion between these lymphoid cells and a depression in their mitotic activity (Oren et al., 1990), suggesting this type of cell behavior regulation is a common theme for members of the tetramembrane spanning family of proteins. For example, antibodies binding to CD9 enhance cell-cell adhesion (Forsyth, 1991; Masellis-Smith and Shaw, 1994) and can decrease the mobility and invasiveness of tumor cells (Miyake et al., 1991). Another family member, KAI1, is the metastatic suppressor for prostate cancer (Dong et al., 1995). Without this protein prostate cells cannot form stable cell contacts and are more capable of metastatic behavior. When the levels of KAI1 are elevated by gene transfection, there is a dramatic decrease in the metastatic behavior of these cells. This theme of stabilizing cellular contacts is also demonstrated by the most recently identified member of the tetramembrane spanning family, late bloomer (Kopczynski et al., 1996). The late bloomer protein is involved in stabilizing the synaptic contact between motor neurons and muscles.

Without this protein the growing axon does not appear to be capable of docking with the muscle fiber. Thus, some members of the tetramembrane spanning family are intimately involved in the formation and maintenance of stable cell contacts, and rTAPA appears to play a similar role in glial cells.

\section{Conclusion}

There is a general increase in the levels of rTAPA as glial cells are born and mature. This increase in the overall levels of rTAPA is 
demonstrated by our immunoblot analysis; however, this type of analysis could not reveal the cellular localization of rTAPA. Sections from the developing brain stained for rTAPA, reveal a clear sequence of cellular labeling. The cells of the ependyma and choroid plexus are the first to express rTAPA, followed by astrocytes and oligodendrocytes. The general increase in rTAPA expression occurs during the second postnatal week, a pivotal point in development,. During this week, astrocytes and oligodendrocytes begin to mature, the structure of the CNS is stabilized, and astrocytes acquire the ability to become reactive. It is during this period that the largest increase in rTAPA is observed, going from $15 \%$ to $70 \%$ of the adult (a five fold increase). To date, all identified members of the tetramembrane spanning family play a role in the molecular cascade leading to the stabilization of cellular contacts. These results, along with family characteristics, indicate a possible role for rTAPA in the stablization of the CNS. 


\section{LIST OF REFERENCES}


Anton, E.S., R.S. Cameron, and P. Rakic (1996) Role of neuron-glial junctional domain proteins in the maintenance and termination of neuronal migration across the embryonic cerebral wall. J. Neurosci. 16: 2283-2293.

Anton, E.S., M. Hadjiargyrou, P.H. Patterson, and W.D. Matthew (1995) CD9 plays a role in Schwann cell migration in vitro. J. Neurosci. 15: 584595.

Ballanyi, K., P. Grafe, and G. Bruggencate (1987) Ion activities and potassium uptake mechanisms of glial cells in guinea-pig olfactory cortex slices. J. Physiol. 382: 159-174.

Barres, B.A., and M. Raff (1996) Axonal control of oligodendrocyte development. In K.R. Jessen and W.D. Richardson (eds): Glial Cell Development, Basic Principles and Clinical Relevance. (pp. 71-83). Oxford, UK: Bios Scientific Publishers.

Berry, M., W.L. Maxwell, A. Logan, A. Mathewson, P. McConnell, D.E. Ashurst, and G.H. Thomas (1983) Deposition of scar tissue in the central nervous system. Acta Neurochirurgica, suppl. 32: 31-53.

Berry, M., and A.W. Rogers (1965) The migration of neuroblasts in the developing cerebral cortex. J Anat. 99: 691-709.

Bignami, A., and D. Dahl (1973) Astrocyte-specific protein and neuroglial differentiation. An immunofluorescence study with antibodies to the glial fibrillary acidic protein. J. Comp. Neur. 153: 27-38.

Caroni, P., and M.E. Schwab (1988) Antibody against myelin-associated inhibitor of neurite growth neutralizes non-permissive substrate properties of CNS white matter. Neuron 1: 85-96.

Caviness, V.S., Jr., and P. Rakic (1978) Mechanisms of cortical development: a view from mutations in mice. Annu. Rev. Neurosci. 1: 297326.

Chou, P.Y., and G.D. Fasman (1974) Prediction of protein conformation. Biochem. 13: 222-245.

Cooper, N.G., and D.A. Steindler (1989) Critical period-dependent alterations of the transient body image in the rodent cerebral cortex. Brain Res. 489:167-176.

Dahl, D. (1981) The vimentin-GFA protein transition in rat neuroglia cytoskeleton occurs at the time of myelination. J. Neurosci. Res. 6: 741748.

Deissler, H., S. Blass-Kampmann, A. Kindler-Rohrborn, H.E. Meyer, and M.F. Rajewsky (1996) Characterization of Rat NCA/CD9 cell surface 
antigen and its expression by normal and malignant neural cells. J. Neruosci. Res. 43: 664-674.

Del Bigio, M.R. (1995) The ependyma: A protective barrier between brain and cerebrospinal fluid. Glia 14: 1-13.

Doherty, P., E. Williams, and F.S. Walsh (1995) A soluble chimeric form of the L1 glycoprotein stimulates neurite outgrowth. Neuron 14: 57-66.

Dong, J.T., P.W. Lamb, C.W. Rinker-Shaeffer, J. Vukanovic, T. Ichikawa, J.R. Isaacs, and J.C. Barrett (1995) KAI1, a metastasis suppressor gene for prostate cancer on human chromosome 11p11.2. Science 268: 884-886.

Dyer, C.A., W.F. Hickey, and E.E. Geisert, Jr. (1991)

Myelin/Oligodendrocyte-specific protein: A novel surface membrane protein that associates with microtubules. J. Neurosci. Res. 28: 607-613.

Eng, L.F., J.J. Vanderhaegen, A. Bignami, and B. Grestl (1971) An acidic protein isolated from fibrous astrocytes. Brain Res. 28: 351-354.

Flaris, N.A., T.L. Densmore, M.C. Molleston and W.F. Hickey (1993) Characterization of microglia and macrophages in the central nervous system of rats: definition of the differential expression of molecules using standard and novel monoclonal antibodies in normal CNS and in four models of parenchymal reaction. Glia 7: 34-40.

Fontana, A., W. Fierz, and H. Wekerle (1984) Astrocytes present myelin basic protein to encephalitogenic T cell lines. Nature 307: 273-275.

Forsyth, K.D. (1991) Anti-CD9 antibodies augment neutrophil adherence to endothelium. Immunology 72: 292.

Garcia-Abreu, J., N.V. Moura, S.L. Carvalho, L.A. Cavalcante (1995) Regionally specific properties of midbrain glia. I. Interactions with midbrain neurons. J. Nerousci. Res. 40:471-477.

Garnier, J., D.J. Osguthorpe, and B. Robson (1978) Analysis of accuracy and implications of simple methods for predicting secondary structure of globular proteins. J. Mol. Biol. 120: 97-120.

Geisert, E.E., Jr., D.J. Bidanset, N. Del Mar, and J.A. Robson (1996a) The upregulation of the keratan sulfate proteoglycan following cortical injury in neonatal rats. Internat. J. Dev. Neurosci. 14: 257-267.

Geisert, E.E., Jr., L.J. Yang, and M.H. Irwin (1996b) Astrocyte growth, reactivity and the target of the antiproliferative antibody, TAPA. J. Neurosci. 16: 5478-5487. 
Geisert, E.E., Jr., and D.J. Bidanset (1993) A central nervous system keratan sulfate proteoglycan: localization to boundaries in the neonatal rat brain. Dev. Brain Res. 75: 163-173.

Geisert, E.E., Jr., T.P. Murphy, M.H. Irwin, and H. Larjava (1991) A novel cell adhesion molecule, G-CAM, found on cultured rat glia. Neurosci. Lett. 133: 262-266.

Giesert, E.E., Jr, and A.M. Stewart (1991) Changing interactions between astrocytes and neurons during CNS maturation. Dev. Biol. 143: 335-345.

Goldman, J.E., R.K.Y. Hirano, and T.N. Seyfried (1984) $\mathrm{G}_{\mathrm{D} 3}$ ganglioside is a glycolipid characteristic of immature neuroectodermal cells. J. Neurosci. 6: 52-60.

Grunwald, G.B., R.S. Pratt, and J. Lilien (1982) Enzymic dissection of embryonic cell adhesive mechanisms. III. Immunological identification of a component of the calcium-dependent adhesive system of embryonic chick neural retina cells. J. Cell Sci. 55: 69-83.

Hadjiargyrou, M., and P.H. Patterson (1995) An anti-CD9 monoclonal antibody promotes adhesion and induces proliferation of Schwann cells in vitro. J. Neurosci. 15: 574-583.

Hardy, R., and R. Reynolds (1991) Proliferation and differentiation potential of rat forebrain oligodendroglial progenitors both in vitro and in vivo. Development 11: 1061-1080.

Hatten, M.E. (1990) Riding the glial monorail: a common mechanism for glial-guided neuronal migration in different regions of the developing brain. Trends Neurosci. 13: 179-184.

Jennings, L.K., C.F. Fox, W.C. Kouns, C.P. Mckay, L.R. Ballou, and H.E. Schults (1990) The activation of human platelets mediated by anti-human platelet p24/CD9 monoclonal antibodies. J. Biol. Chem. 265: 3815-3822.

Joosten, E.A., and A.A. Gribnau (1989) Astrocytes and guidance of outgrowing corticospinal tract axons in the rat. An immunocytochemical study using ani-vimentin and anti-glial fibrillary acidic proten. Neuroscience 31: 439-452.

Kaprielian, Z., K.-O. Cho, M. Hadjargyrou, and P.H. Patterson (1995) CD9, a major platelet cell surface glycoprotein, is a ROCA antigen and is expressed in the nervous system. J. Neurosci. 15: 562-573.

Kaprielian, Z., and P.H. Patterson (1993) Surface and cytoskeletal markers of rostrocaudal position in the mammalian nervous system. J. Neurosci. 13: 2495-2508. 
Komuro, H., and P. Rakic (1993) Modulation of neuronal migration by NMDA receptors. Science 260: 95-97.

Kopczynski, C.C., G.W. Davis, and C.S. Goodman (1996) The neural tetraspanin, encoded by late bloomer, that facilitates synapse formation. Science 271: 1867-1870.

Levi, G., F. Aloisi, and G.P. Wilkin (1987) Differentiation of cerebellar bipotential glial precursors into oligodendrocytes in primary culture: development profile of surface antigens and mitotic activity. J. Neurosci. Res. 18: 407-417.

LeVine, S.M., and J.E. Goldman (1988) Embryonic divergence of oligodendrocyte and astrocyte lineages in developing rat cerebrum. J. Neurosci. 8: 3992-4006.

Lillien, L.E., and M.C. Raff (1990) Differentiation signals in the CNS: type2 astrocyte development in vitro as a model syste. Neuron 5:111-119.

Ling, E.A., and C.P. Leblond (1973) Investigation of glial cells in semithin sections. II. Variations with age in the numbers of the various glial cell types in rat cortex and corpus callosum. J. Comp. Neurol. 149: 73-82.

Linington, C., M. Webb, and P.L. Woodhams (1984) A novel myelinassociated glycoprotein defined by a mouse monoclonal antibody. J. Neuroimmunol. 6: 387-396.

Masellis-Smith, A., and A.R.E. Shaw (1994) Anti-CD9 monoclonal antibody induce pre-B cell adhesion to bone marrow fibroblasts through de novo recognition of fibronectin. J. Immunol. 152: 2768-2777.

McMorris, F.A. (1983) Cyclic AMP induction of the myelin enzyme 2',2'cyclic nucleotide 3'-phosphohydrolase in rat oligodendrocytes. J. Neurochem. 41: 506-515.

Miller, R.H. (1996) Oligodendrocyte origins. Trends Neurosci. 19: 92-96.

Misson, J.-P., T. Takahishi, and V.S. Caviness (1991) Ontogeny of radial and other astroglial cells in murine cerebral cortex. Glia 4: 138-148.

Miyake, M., M. Koyama, M. Seno, and S. Ikeyama (1991) Identification of the motility-related proteins (MRP-1), recognized by monoclonal antibody M31-15, which inhibits cell motility. J. Exp. Med. 174: 1347.

Nakamura, K., R. Iwamoto, and E. Mekada (1995) Membrane-anchored heparin-binding EGF-like growth factor (HB-EGF) and diphtheria toxin receptor-associated protein (DRAP27)/CD9 forms a complex with integrin $\alpha 3 \beta 1$ at cell-cell contact sites. J. Cell Biol. 129: 1691-1705. 
Nakamura, Y., R. Iwamoto, and E. Mekada (1996) Expression and distribution of CD9 in myelin of the central and peripheral nervous system. Amer. J. of Path. 149: 575-583.

Navascues, J., G.L. Rodriguez, M.V. Garcia, I.S. Alvarez, P.G. Martin (9187) Extra-axonal environment and fibre directionality in the early development of the chick embryo optic chiasm: a light and scanning electron microscopic study. J. Neurocytol. 16:299-310.

Oren, R., S. Takahashi, C. Doss, R. Levy, and S. Levy (1990) TAPA-1, the target of an antiproliferative antibody, defines a new family of transmembrane proteins. Molecular and Cellular Biol. 10: 4007-4015.

Parnavelas, J.G., R. Luder, S.G. Pollard, K. Sullivan, and A.R. Lieberman (1983) A qualitative and quantitative ultrastructural study of glial cells in the developing visual cortex or the rat. Philos. Trans. R. Soc. London, B 301: 55-84.

Pixley, S.K.R., and J. de Vellis (1984) Transition between immature radial glia and mature astrocytes studied with a monoclonal antibody to vimentin. Dev. Bran Res. 15: 201-209.

Quarles, R.H., D.R. Colman, J.L. Salzer, and B.D. Trapp. (1992). Myelinassociated glycoprotein: structure-function relationships and involvement in neurological diseases. In R. E. Martenson (Ed.), Myelin: Biology and Chemistry (pp. 413-448). Boca Raton, FL: CRC Press.

Raff, M.C., R.H. Miller, and M. Noble (1983) A glial progenitor cell that develops in vitro into an astrocyte or an oligodendrocyte depending on cultrue medium. Nature 303:390-396.

Raff, M.C., K.L. Fields, S.-I. Hankomori, R. Mirsky, R.M. Pruss, and J. Winter (1979) Cell-type-specific markers for distinguishing and studying neurons and the major classes of glial cells in culture. Brain Res. 174: 283308.

Raff, M.C., R. Mirsky, K.L. Fields, R.P. Lisak, S.H. Dorfman, D.H. Silberberg, N.A. Gregson, S. Leibowitz, and M.C. Kennedy (1978) Galactocerebroside is a specific cell-surface antigenic marker for oligodendrocytes in culture. Nature 274: 813-816.

Rakic, P. (1995) Radial glial cells: scaffolding for brain construction. In: Kettenmann H. Ransom BR (eds) Neuroglia. (pp. 746-762). Oxford Univrsity Press, New York. .

Rakic, P. (1971) Neuron-glia relationship during granule cell migration in developing cerebellar cortx. A golgi and electronmicroscopic study in macacus Rhesus. J. Comp. Neurol. 141: 238-312. 
Reier, P.J., and J.D. Houle. (1988). The glial scar: its bearing on axonal regeneration and transplantation approaches to CNS repair. In S. G.

Waxman (Ed.), Advances in neurology: functional recovery in neurological diseases (pp. 87-138). New York: Raven.

Reynolds, R., and G.P. Wilkin (1988) Development of macroglial cells in rat cerebellum II. An in situ immunohistochemical study of oligodendroglial lineage from precursor to mature myelinating cell. Development 102: 409-425.

Salzer, J.L., L. Pedraza, M. Brown, A. Struyk, D. Afar, and J. Bell (1990) Structure and function of the myelin-associated glycoprotein. Ann. N.Y. Acad. Sci. 605: 302-312.

Secrist, H., S. Levy, R.H. DeKruyff, and D.T. Umetse (1996) Ligation of TAPA-1 (CD81) or major histocompatibility complex class II in co-cultures of human B and T lymphocytes enhances interleukin-4 synthesis by antigen-specific CD4+ T cells.

Schick, M.R., V.Q. Nguyen, and S. Levy (1993) Anti-TAPA-1 antibodies induce protein tyrosine phosphorylation that is prevented by increasing intracellular thiol levels. J. Immunol. 151: 1918-1925.

Shapiro, L., A.M. Fannon, P.D. Kwong, A. Thompson, M.S. Lehmann, G. Grubel, J.-F. Legrand, J. Als-Nielsen, D.R. Colman, and W.A. Hendrickson (1995) Structural basis of cell-cell adhesion by cadherins. Nature 374: $327-$ 337.

Silver J. (1993) Glia-neuron interactions at the midline of the developing mammalian brain and spinal cord. Perspect. Dev. Neurobiol. 1:227-236.

Silver, J., M. Poston, U. Rutishauser (1987) Axon pathway boundaries in the developing brain. I. Cellular and molecular determinants that separate the optic and olfactory projections. J. Neurosci. 7:2264-2272.

Silver, J. (1984) Studies on the factors that govern directionality of axonal growth in the embryonic optic nerve and at the chiasm of mice. J. Comp. Neurol. 223:238-251.

Silver, J., and U. Rutishauser (1984) Guidance of optic axons in vivo by a preformed adhesive pathway on neuroepithelial endfeet. Dev. Biol. 106: 485-499.

Slupsky, R., Jr, J.G. Seehafer, S.C. Tang, A. Masellis-Smith, and A.R.E. Shaw (1989) Evidence that monoclonal antibodies against CD9 antigen induce specific associations between CD9 and the platelet glycoproteins IIb-IIIa complex. J. Biol. Chem. 264: 12289-12293. 
Steindler, D.A., T.F. O'Brien, E. Laywell, K. Harrington, A. Faissner, and M. Schachner (1990) Boundaries during normal and abnormal brain development: In vivo and in vitro studies of glia and glycoconjugates. Exp. Neurol. 109: 35-56.

Takahashi, S., C. Doss, S. Levy, and R. Levy (1990) TAPA-1, The target of an antiproliferative antibody is associated on the cell surface with the Leu13 antigen. J. Immunol. 145: 2207-2213.

Takiguchi, M., and J.A. Frelinger (1986) Induction of antigen presentation ability in purified cultures of astroglia by interferon-gamma. J. Mol. Cell. Immunol. 2: 269-280.

Virtaneva, K.I., P. Angelisová, T. Baumruker, V. Horejsi, H. Nevanlinna, and J. Schröder (1993) The gene for CD37, CD53, and R2, all members of a novel gene family, are located on different chromosomes. Immunogenetics 37: 461-465.

Walz, W., and L. Hertz (1982) Ouabain-sensitive and ouabain-resistant net uptake of potassium into astrocytes and neurons in primary cultures. J. Neurochem. 39: 70-77.

Wechsler, W., and K. Meller (1967) Electron microscopy of neuronal and glial differentiation in the developing brain of the chick. Prog. Brain Res. 26:93-144.

Weir, M.D., A.J. Patel, A. Hunt, and D.G.T. Thomas (1984) Developmental changes in the amount of glial fibrillary acidic protein in three regions of the rat brain. Dev. Brain Res. 15: 147-154.

Wilkinson, D.G., J.A. Bailes, A.P. McMahon (1987) Expression of the proto-oncogene int- 1 is restricted to specific neural cells in the developing mouse embryo. Cell 50:79-88.

Yatomi, Y., Y. Ozaki, K. Satoh, and S. Kume (1993) Anti-CD9 monoclonal antibody elicits staurosporine inhibitable phosphatidylinositol 4,5-

bisphosphate hydrolysis, phosphatidylinositol 3,4-bisphosphate synthesis, and protein-tyrosine phosphorylation in human platelets. FEBS 322: 285290.

Zerlin, M., S.W. Levison, and J.E. Goldman (1995) Early patterns of migration, morphogenesis, and intermediate filament expression of subventricular zone cells in the postnatal rat forebrain. J. Neurosci. 15:7238-7249. 


\section{VITA}

Mr. Clyde Sullivan was born on October 11, 1971 in Memphis, Tennessee. He graduated from Collierville High School in 1989 and received a Bachelors Degree in Biology from Troy State University in 1993. 



\section{STATEMENT OF PERMISSION TO USE}

In presenting this thesis in partial fulfillment of the requirements for a master's degree at The University of Tennessee, Memphis, I agree that the Library shall make it available to borrowers under rules of the Library. Brief quotations from this thesis are allowable with-out special permission, provided that accurate acknowledgment of the source is made.

Permission for extensive quotation from or reproduction of this thesis may be granted by my research advisor, or in [his/her] absence, by the head of Interlibrary Services when, in the opinion of either, the proposed use of the material is for scholarly purposes. Any copying or use of the material in this thesis for financial gain shall not be allowed without my written permission.

Signature

Date 